\title{
Profesiones jurídicas, formación jurídica y litigiosidad de una sociedad en evolución: el caso de España.
}

\section{Manuel Ortells Ramos}

\section{Nota previa}

Las siguientes páginas, pesadas por su sequedad, pero tal vez útiles por los datos que ofrecen, constituyeron el informe espańol al tema "La formación jurídica en una sociedad contenciosa en evolución", uno de los que han sido tratados en el XI Congreso de la Asociación Internacional de Derecho Procesal, celebrado en Viena, en agosto de 1999.

\section{Descripción de las profesiones jurídicas en España}

1.1 Las profesiones jurídicas, en especial las relacionadas con la justicia civil, y el número de sus efectivos

\subsubsection{Jueces y magistrados integrantes de la carrera judicial}

La carrera judicial consta de tres categorías: Magistrado del Tribunal Supremo, Magistrado, Juez. Su función es ejercer la potestad jurisdiccional en las diferentes clases de tribunales. Por regla general establecida por la Constitución, la potestad jurisdiccional sólo puede ser atribuida a órganos integrados por estos empleados públicos (o por los que, temporalmente para resolver problemas de gestión de plantillas, pueden desempeñar sus funciones, según veremos en el apartado siguiente). La Constitución reconoce, como excepción, tribunales especiales cuyos integrantes no pertenecen a la carrera judicial: tribunales militares, Tribunal de Cuentas, Tribunal Constitucional, Tribunal del Jurado competente en algunas materias penales, tribunales consuetudinarios y tradicionales -entre los que la Ley Orgánica del Poder judicial 
ha reconocido al Tribunal de las Aguas de la Vega Valenciana-. Los jueces de paz no pueden ser considerados como incluidos en la última excepción, pero han sido mantenidos por la LOPJ, sin que se hayan planteado dudas de constitucionalidad. Sobre el número de efectivos se informa en el siguiente apartado 2 .

\subsubsection{Jueces no profesionales: jueces de paz.}

No es requisito para ser juez de paz ser licenciado en Derecho. Son elegidos por el pleno del Ayuntamiento del municipio donde existen juzgados de paz-que son todos aquellos donde no existen juzgados de primera instancia-. La competencia de estos juzgados en materia civil es: conciliación previa no obligatoria, asuntos litigiosos de cuantía no superior a 8,000 pesetas, funciones de Registro Civil. Sobre el número de efectivos véase, también, el siguiente apartado 2 .

\subsubsection{Otros jueces no profesionales}

a) Magistrados suplentes: son nombrados anualmente por el Consejo General del Poder Judicial entre personas que reúnen los requisitos para ingresar en la carrera judicial. Su función es formar parte de los tribunales colegiados cuando no haya suficientes magistrados de carrera necesarios para constituirlos válidamente. b) Jueces sustitutos: se diferencian de los anteriores en que cumplen su función en órganos unipersonales cuando las necesarias sustituciones del titular no se han podido realizar con otros miembros de la carrera judicial. c) Jueces en régimen de provisión temporal: han de reunir los requisitos para acceder a la carrera judicial, son nombrados por la Sala de Gobierno de los tribunales superiores de justicia previo concurso de méritos entre los aspirantes. Su función es ocupar temporalmente las plazas que han quedado vacantes en los concursos de traslados entre miembros de la carrera judicial, si los órganos de gobierno del Poder Judicial estiman que la situación no puede resolverse adecuadamente con aplicación del régimen de sustituciones. Sobre el número de efectivos véase el siguiente apartado 2 .

\subsubsection{Cuerpo de secretarios judiciales}

Son licenciados en Derecho que han debido realizar las pruebas selectivas de acceso al Cuerpo, aunque también están previstos sistemas de desempeño provisional de funciones. Integrados en la organización 
de los tribunales de justicia, sus principales funciones son el ejercicio de la fe pública judicial y colaborar con el juez en la dirección del procedimiento. El número de efectivos de esta profesión es, al 30 de junio de 1997, el siguiente: primera categoría: 44; segunda categoría: 1.921; tercera categoría: 564 ; total: $2.529 .{ }^{1}$

\subsubsection{Cuerpos de oficiales, auxiliares y agentes judiciales}

No se requiere que sean licenciados en Derecho. Desempeñan dentro de los tribunales de justicia diversas funciones de colaboración material para la realización de los procedimientos y para el funcionamiento general del órgano.

\subsubsection{Abogados}

Licenciados en Derecho que ejercen profesionalmente la dirección y defensa de las partes en toda clase de procesos judiciales y funciones extrajudiciales de asesoramiento y consejo jurídicos. Por regla general han de estar inscritos en algún colegio profesional, salvo que actúen al servicio de administraciones o entidades públicas con relación de dependencia funcionarial o laboral. El número de efectivos de esta profesión, limitado a los abogados inscritos como ejercientes, es, al 31 de diciembre de 1997, de 93,387; de los cuales 23,127 están inscritos en el Colegio de Madrid; 10,673 en el de Barcelona; 5,512 en el de Valencia; $y, 3679$ en el de Sevilla. ${ }^{2}$,

\subsubsection{Procuradores de los Tribunales}

Licenciados en Derecho, inscritos en el correspondiente colegio profesional, que ejercen profesionalmente funciones de representación de las partes ante los tribunales, en el doble sentido de que actúan ante estos en nombre de aquellas -y bajo la dirección del abogado si está legalmente prescrita-, y de que reciben, en nombre de la parte, las resoluciones de los tribunales y los actos de la parte contraria. El número de efectivos de esta profesión es, en julio de 1998 , de 8,428 . $^{3}$

1 Fuente: último escalafón del Cuerpo de Secretarios cerrado a 30 de junio de 1997. Agradezco la colaboración de D. Román Albaladejo.

2 Fuente: información facilitada por los servicios del Consejo General de la Abogacía Española, cuya colaboración agradezco.

3 Fuente: información facilitada por los servicios del Consejo General de los Ilustres Colegios de Procuradores de los Tribunales de España, cuya colaboración agradezco. 


\subsubsection{Graduados sociales}

Son titulados universitarios de grado medio (diplomados) que, inscritos en el colegio profesional correspondiente, ejercen funciones de asesoramiento en materias de Derecho del Trabajo y de la Seguridad Social y además pueden representar a los interesados en los procedimientos judiciales y administrativos sobre las materias citadas. Sólo en la Comunidad Autónoma de Madrid están inscritos más de 3,000 profesionales, que prestan servicios a más de quince mil empresas. ${ }^{4}$

\subsubsection{Ministerio Fiscal}

Licenciados en Derecho que acceden por oposición a un Cuerpo único. Sus funciones se ejercen principalmente en materia penal. En materia civil en sentido amplio también tienen funciones importantes: han de ser parte -con matices no procedentes ahora- en procesos sobre materias de estado civil (cuestiones matrimoniales, de filiación, de incapacitación), de protección de derechos fundamentales; pueden interponer recurso para unificar la interpretación de normas en el proceso especial sobre materias de trabajo y de seguridad social; intervienen mediante informe antes de resoluciones sobre temas de jurisdicción y competencia de los tribunales y de tramitación de recursos de casación. El número de efectivos de la Carrera Fiscal, a fecha de 1 de enero de 1995 , era de $1.244 .{ }^{5}$

\subsubsection{Notarios}

Licenciados en Derecho que acceden mediante oposición gestionada por los poderes públicos al ejercicio de una profesión que tiene reguladas sus funciones, número y ámbito territorial del establecimiento profesional y honorarios por prestación de los servicios. Sus funciones son la intervención, con el efecto jurídico de fehaciencia, en los negocios y actos jurídicos privados, la documentación de los mismos y el asesoramiento para que, en la realización de esos actos y negocios, se cumplan las normas legales imperativas y los interesados estén advertidos de cómo expresar su voluntad para conseguir los resultados perseguidos. Los documentos que elaboran tienen un especial efecto probatorio en los procesos y son requisito necesario para el acceso de determinadas transaccio-

4 Fuente: Web del Colegio de Graduados Sociales de Madrid.

5 Fuente: Libro Blanco del Ministerio Fiscal, Ministerio de Justicia, Madrid, 1996, pp. 323-344. 
nes a Registros Públicos, muy destacadamente las transacciones inmobiliarias al Registro de la Propiedad. Los datos de los que he podido disponer sobre el número de efectivos de esta profesión se refieren a 1993, año en el que había 2,006 notarios, con establecimiento en todo el territorio, con oficinas cuyo tamaño y volumen de trabajo es muy diferenciado. ${ }^{6}$

\subsubsection{Corredores de Comercio}

Licenciados universitarios no sólo en Derecho sino también en ciencias económicas y empresariales, que acceden, mediante oposición gestionada por los poderes públicos, a una profesión cuyas competencias, retribuciones y establecimiento están regulados por normas. Sus funciones son: intervenir y documentar, con formas distintas a la notarial y ajustadas a la agilidad especial del tráfico jurídico mercantil, pero también con efecto jurídico de fehaciencia, los negocios y actos de ese sector del tráfico jurídico y asesorar en la celebración de los mismos. Actualmente, el Corredor, como fedatario especializado en el ámbito económico y mercantil, interviene prácticamente la totalidad de los negocios bancarios, préstamos, créditos, avales, contragarantías, transmisiones de valores, pignoraciones, contratos de garantía mercantil, así como los contratos de leasing, factoring, cesiones de crédito, entre otros.

\subsubsection{Registradores de la Propiedad y Mercantiles}

Licenciados en Derecho que acceden, mediante oposición, al ejercicio de una función pública pero prestada por profesionales independientes (que asumen el coste de los medios personales, materiales y organizativos para prestar el servicio), sometidos a una regulación jurídico-pública del acceso a la profesión, del desempeño de la misma y de las retribuciones. La función consiste en la realización, en los registros públicos a su cargo, de los asientos sobre la titularidad de derechos reales sobre bienes inmuebles, negocios jurídicos y actos con trascendencia sobre esa titularidad, negocios jurídicos respecto a determinados bienes muebles que pueden tener acceso a registro público (hipotecas y prendas sobre los mismos, operaciones de compraventa a plazos y leasing), actos y negocios jurídicos del tráfico mercantil con acceso al Registro (constitución de sociedades mercantiles y actos esenciales de la vida social, establecimiento de sucursales, entre otros). 


\subsection{Número de jueces (profesionales y legos, a tiempo completo o parcial, hombres y mujeres)}

En el apartado anterior se ha dado información sobre el número de efectivos de aquellas profesiones jurídicas cuyos datos estaban disponibles. En este apartado se destaca esa información especialmente respecto a los jueces y magistrados. Los del apartado 1 son profesionales a tiempo completo. Los de los apartados 2,3 y 4 no son profesionales de la Judicatura, aunque sí licenciados en Derecho, y desempeñan sus funciones interinamente.

1.2.1 Total de jueces y magistrados integrantes de la Carrera Judicial, y que prestan servicios en el Tribunal Supremo y en los diferentes órganos colegiados y unipersonales, a fecha 19 de febrero de 1997: 3,221. ${ }^{7}$

En cuanto a la distribución entre hombres y mujeres, a falta de información más actualizada en el Libro Blanco de la Justicia y en la Memoria del Consejo General del Poder Judicial de 1997, mencionaré datos relativos al 31 de enero de 1986: el número de mujeres jueces en ese momento suponía el $11 \%$, tendiendo a incrementarse, dado que en la promoción última que pudo contabilizarse en un trabajo editado en 1987, las mujeres constituían prácticamente el $50 \%$ de la promoción. ${ }^{8}$

1.2.2 Magistrados suplentes nombrados para el año judicial 1996$1997: 381 .^{9}$

1.2.3 Jueces sustitutos nombrados para el año judicial 1996-1997: $995 .{ }^{10}$

1.2.4 Jueces en régimen de provisión temporal nombrados para el año judicial 1996-1997: $141 .^{11}$

7 Consejo General del Poder Judicial, Memoria que el Consejo general del Poder Judicial eleva a las Cortes Generales, Madrid, 1997, p. 203.

8 J.J. Toharia, "i Pleitos tengas!..". Introducción a la cultura legal española, Madrid, 1987, pp. $15-16$.

9 Consejo General del Poder Judicial, Libro Blanco de la Justicia, Madrid, 1997, p. 95.

10 Consejo General del Poder Judicial, Libro Blanco de la Justicia, Madrid, 1997, p. 95.

11 Consejo General del Poder Judicial, Libro Blanco de la Justicia, Madrid, 1997, p. 95. 


\subsection{La población de España}

La población española, según el censo de 1996, era de 39'669,394 habitantes. De estos, 24'942,210 viven en poblaciones de más de 20,000 habitantes. ${ }^{12}$

\subsection{Evolución de las cifras anteriores desde principios de siglo}

No es posible ofrecer una exposición de conjunto, completa y coherente, de la evolución desde 1900 a la actualidad de las cifras de población y de efectivos de las profesiones jurídicas. Los datos que están disponibles, elaborados por expertos, son fragmentarios en cuanto a los períodos temporales considerados y no homogéneos en cuanto a la elaboración de los datos. Me limitaré a presentar tres tablas algo significativas.

\subsubsection{Población española 1900-1996.13}

\begin{tabular}{|ccc|}
\hline Año del censo & Población & Crecimiento \\
\hline 1900 & 18.617 .956 & 509.346 \\
1910 & 19.992 .451 & 1.374 .495 \\
1920 & 21.508 .135 & 1.515 .684 \\
1930 & 23.844 .796 & 2.336 .661 \\
1940 & 26.187 .899 & 2.343 .103 \\
1950 & 28.368 .642 & 2.180 .743 \\
1960 & 30.903 .137 & 2.534 .495 \\
1970 & 34.041 .531 & 3.138 .394 \\
1975 & 36.012 .682 & 1.971 .151 \\
1981 & 37.682 .355 & 1.669 .673 \\
1986 & 38.473 .418 & 791.063 \\
1991 & 38.872 .268 & 398.850 \\
1996 & 39.669 .394 & 797.126 \\
\hline
\end{tabular}

12 Fuente: Anuario El País 1998, pp. 387-388, a partir de datos del Instituto Nacional de Estadística.

13 Fuente: Anuario El País 1998, p. 387, a partir de datos del Instituto Nacional de Estadística. 
1.4.2 Número de plazas de juez y magistrado creadas anualmente en tribunales con competencia civil en sentido amplio, desde la promulgación de la Ley de Demarcación y Planta Judicial, dictada a consecuencia de la Ley Orgánica del Poder Judicial de $1985 .{ }^{14}$

\begin{tabular}{|cc|}
\hline Año de creación & Número de plazas creadas \\
\hline 1989 & 210 \\
1990 & 178 \\
1991 & 216 \\
1992 & 42 \\
1993 & 29 \\
1994 & 13 \\
1995 & 45 \\
1996 & 38 \\
\hline
\end{tabular}

1.4.3 Censo de abogados ejercientes 1909-1991. ${ }^{15}$

\begin{tabular}{|c|c|c|}
\hline Afío & $\begin{array}{l}\text { Número de } \\
\text { abogados }\end{array}$ & $\begin{array}{l}\text { Abogados por millón } \\
\text { de habitantes }\end{array}$ \\
\hline 1909 & 6.368 & \\
\hline 1914 & 8.137 & \\
\hline 1915 & 7.276 & \\
\hline 1916 & 7.076 & \\
\hline 1917 & 7.596 & \\
\hline 1932 & 9.018 & \\
\hline 1933 & 10.278 & \\
\hline 1939 & 5.971 & \\
\hline 1940 & 4.232 & \\
\hline 1941 & 4.308 & \\
\hline 1942 & 4.515 & \\
\hline
\end{tabular}

14 Fuente: Consejo General del Poder Judicial, Memoria que el Consejo general del Poder Judicial eleva a las Cortes Generales, Madrid, 1997, p. 200.

15 Los datos desde 1909 a 1969 proceden de J.J. Toharia Cortés, Cambio social y vida jurídica en España, Madrid, 1974, p. 213; los datos desde 1980 en adelante, de S. Pastor Prieto, iAh de la justicia! Política judicial y economia, Madrid, 1993, p. 276. 


\begin{tabular}{|ccc|}
\hline Año & $\begin{array}{c}\text { Número de } \\
\text { abogados }\end{array}$ & $\begin{array}{c}\text { Abogados por millón } \\
\text { de habitantes }\end{array}$ \\
\hline 1943 & 5.629 & \\
1969 & 15.874 & 748 \\
1980 & 41.098 & 777 \\
1981 & 43.626 & 841 \\
1982 & 48.303 & 901 \\
1983 & 48.956 & 946 \\
1984 & 52.067 & 1.006 \\
1985 & 55.736 & 1.089 \\
1986 & 61.045 & 1.147 \\
1987 & 63.860 & 1.219 \\
1988 & 68.264 & 1.450 \\
1989 & 81.453 & 1.380 \\
1990 & 77.688 & 1.281 \\
1991 & 72.729 & \\
\hline
\end{tabular}

\subsection{Comparación con la evolución de la litigiosidad civil durante el mismo período}

El método sociológico aplicado al Derecho en el contexto español no tiene gran tradición. Sólo en tiempos relativamente recientes han empezado a elaborarse y publicarse estudios dedicados al análisis sociológico y económico de la realidad socio-jurídica española, realizados con una metodología adecuada a ese objeto. ${ }^{16}$ Por otra parte, la exhaustividad y plena fiabilidad de tales estudios realizados por especialistas se enfrenta con el obstáculo de la falta de unas estadísticas judiciales suficientemente desagregadas, fiables en las cifras que ofrecen, elaboradas con puntualidad temporal y relativas a series temporales bastante largas para realizar análisis comparativos de períodos prolongados. ${ }^{17}$

16 A los que ya han sido citados hasta ahora, deben añadirse el trabajo pionero de J.J. Toharia Cortés, Cambio social y vida jurídica en España, Madrid, 1974; M. Roig Alonso, Economia de la Justicia (Un primer análisis del caso español, Facultat de Ciències Económiques i Empresarials, Universitat de València, Quaderns de treball, número 15, abril, 1988.

17 El Consejo General del Poder Judicial, Libro Blanco de la Justicia, Madrid, 1997, p. 67 , reconoce que "la estadística actual -...- no es la estadística fiable y cualitativa que precisa la Administración de Justicia». 
Este problema afectará de modo importante a la información que se pide dentro de este apartado, y también a la de aquellos apartados que requieran referencias estadísticas.

Desde una perspectiva de no especialista -como es la del profesor que elabora este informe- resulta adecuado limitarse a exponer la conclusiones a las que hasta ahora han llegado los especialistas y, si es conveniente, reproducir las series temporales consideradas por ellos.

\subsubsection{Período 1900 a 1970}

Ha sido estudiado por Toharia Cortés en su obra «Cambio social y vida jurídica en España". ${ }^{18}$

El objetivo de su análisis era comprobar la incidencia del llamado «desarrollo económico español» en la evolución de la realidad jurídica española.

En el período 1900-1959 la economía española no experimentó cambios estructurales profundos. Estos se produjeron a partir de la década 1960-1970. Específicamente: decrecimiento progresivo de la población activa agraria e incremento de la ocupada en los sectores industrial y de servicios; la tasa anual de crecimiento de la renta per capita se situaba en cifras muy bajas hasta 1960, año en el que se inició con continuidad una mayor tasa de crecimiento; aumento importante de la constitución de sociedades anónimas (entre 1910-1920 se constituyeron 4.862; entre 1940-1950: 7.827; entre 1950-1960: 10.576; 1961-1968: 26.631); aumento muy notable de la población residente en localidades de mayor tamaño.

Para investigar la repercusión de estos cambios socioeconómicos en la realidad jurídica del Derecho Privado, Toharia distingue entre la que llama vida jurídica civil, que se desarrolla fuera de la actividad de los tribunales de justicia, y la vida judicial civil.

Para examinar la evolución de la vida jurídica civil utiliza el indicador del número de actos notariales.

En el aspecto cuantitativo la evolución producida la ilustra esta tabla que recoge las tasas de actividad notarial en España en el período 1900-1970 (número de actos notariales por cada 1.000 habitantes). ${ }^{19}$

18 Editada en Madrid, 1974. Lo que se expone en el texto es -mientras no se indique lo rontrario- un resumen de los contenidos más importantes de esa obra, útiles para este informe.

19 Tabla procedente de J.J. Toharia Cortés, Cambio social y vida juridica en España, Madrid, 1974, p.155. 


\begin{tabular}{|cc|}
\hline Años & Número actos por \\
$\mathbf{1 . 0 0 0}$ habitantes
\end{tabular}

En cuanto a los cambios en la composición cualitativa de la actividad notarial, Toharia hace notar que los contratos en general y los protestos de los documentos de giro aumentan de modo considerable (1950: 63,4 por ciento del total; 1969: 72,5 por ciento del total), mientras que descienden los actos considerados como tradicionales de la intervención notarial (los actos respecto a sucesiones hereditarias y contratos por razón de matrimonio pasan del 12,2 por ciento en 1950 al 5 por ciento en 1969).

La evolución de la vida judicial civil se aprecia con el número de asuntos ingresados en los tribunales de justicia y examinando la composición cualitativa de la demanda judicial.

La siguiente tabla refleja el número de asuntos contenciosos ingresados en los juzgados de primera instancia y la tasa de asuntos por cada mil habitantes. ${ }^{20}$

20 Tabla procedente de J.J. Toharia Cortés, Cambio social y vida jurídica en España, Madrid, 1974, p. 173. 


\begin{tabular}{|ccc|}
\hline Años & $\begin{array}{c}\text { Número de } \\
\text { asuntos }\end{array}$ & $\begin{array}{c}\text { Número por } \\
\mathbf{1 . 0 0 0} \text { habitantes }\end{array}$ \\
\hline 1906 & 28.985 & 1,44 \\
1940 & 78.836 & 3,01 \\
1945 & 46.633 & - \\
1950 & 62.545 & 2,20 \\
1953 & 50.190 & 1,76 \\
1954 & 55.035 & 1,91 \\
1955 & 53.710 & 1,85 \\
1956 & 51.542 & 1,76 \\
1957 & 50.105 & 1,70 \\
1958 & 53.415 & 1,78 \\
1959 & 55.987 & 1,86 \\
1960 & 56.894 & 1,87 \\
1961 & 57.611 & 1,89 \\
1962 & 59.556 & 1,93 \\
1963 & 56.436 & 2,10 \\
1964 & 67.093 & 2,14 \\
1965 & 67.256 & 2,12 \\
1966 & 67.105 & 2,10 \\
1967 & 64.384 & 2,00 \\
1968 & 57.808 & 1,71 \\
1969 & 62.483 & 1,83 \\
\hline & & \\
\hline & & \\
\hline
\end{tabular}

El análisis de estos datos conduce a Toharia a destacar el escaso aumento de la litigiosidad civil y mercantil a pesar de los cambios socioeconómicos producidos y del notable incremento de la actividad en la vida jurídica civil. Habría que realizar una matización: si a las cifras que Toharia considera, se añadieran las de los asuntos de la competencia de los juzgados municipales y comarcales, el número de asuntos civiles en primera instancia experimentaría un notable incremento.

En cuanto a la composición cualitativa de la litigiosidad civil es ilustrativa la siguiente tabla, que refleja la tasa por cien mil habitantes de asuntos resueltos, en total y en las cuatro clases de asuntos cuantitativamente predominantes en los Juzgados de Primera Instancia. ${ }^{21}$

21 Tabla procedente de J.J. Toharia Cortés Cambio social y vida juridica en España, Madrid, 1974, p. 176. 


\begin{tabular}{|cccccc|}
\hline Años & Total & $\begin{array}{c}\text { Proceso } \\
\text { ordinario } \\
\text { mayor valor }\end{array}$ & $\begin{array}{c}\text { Proceso } \\
\text { ordinario } \\
\text { menor valor }\end{array}$ & $\begin{array}{c}\text { Sucesiones } \\
\text { menoceso sumario }\end{array}$ & $\begin{array}{c}\text { Proces } \\
\text { deudas especial } \\
\text { documentación }\end{array}$ \\
\hline 1953 & 125,6 & 5,7 & - & - & - \\
1954 & 133,2 & 7,2 & - & - & - \\
1955 & 131,6 & 6,5 & 7,6 & 49,2 & $-19,0$ \\
1956 & 124,5 & 4,0 & - & - & - \\
1957 & 119,5 & 4,0 & - & - & 31,3 \\
1958 & 125,5 & 3,6 & 10,4 & 57,0 & 40,0 \\
1959 & 127,3 & 3,8 & 10,3 & 50,4 & 46,9 \\
1960 & 128,7 & 4,0 & 11,3 & 45,1 & 50,3 \\
1961 & 129,0 & 4,1 & 12,1 & 44,7 & 61,3 \\
1962 & 131,9 & 4,3 & 12,4 & 45,0 & 68,0 \\
1963 & 142,3 & 4,6 & 12,9 & 46,2 & 63,3 \\
1964 & 147,0 & 4,2 & 11,2 & 45,9 & 62,3 \\
1965 & 142,4 & 4,1 & 11,4 & 47,6 & 58,1 \\
1966 & 142,9 & 4,5 & 12,2 & 47,6 & \\
1967 & 134,3 & 3,6 & 10,5 & 47,9 & \\
\hline
\end{tabular}

La importancia que mantiene los asuntos de sucesiones llama la atención a Toharia. Probablemente se explica porque en esa clase de asuntos han sido incluidas las declaraciones judiciales de herederos en los casos de falta de testamento, que no es procedimiento de jurisdicción contenciosa. Si es así, el mantenimiento de esa importancia cuantitativa no supondría ninguna peculiaridad de la litigiosidad civil.

La apreciación final de Toharia sobre la evolución de la vida judicial civil es la de que el incremento muy importante de la vida jurídica civil ha coexistido a finales de este período con una evasión de los tribunales civiles de un número también importante de potenciales litigios. Para Toharia las causas de esto son, junto a las tradicionales de la lentitud y coste de los procesos judiciales, la inadecuación de estos procedimientos y de la actitud de los jueces frente a un nuevo tipo de litigio. Este nuevo tipo de litigio se caracterizaría por ser más una cuestión de intereses a componer, que una cuestión de Derecho a resolver: a su vez, los jueces estarían formados más para lo segundo que para lo primero.

Civiles en sentido amplio son los asuntos en materia de Derecho del trabajo y de la Seguridad Social, que en este período estaban atribuidos a la competencia de tribunales especiales integrados, después de la guerra civil, por jueces técnicos. La siguiente tabla refleja los asuntos presen- 
tados ante los tribunales de trabajo de primera instancia. ${ }^{22}$ Puede observarse que estos asuntos experimentan un notable incremento a partir de la mitad de la década de 1960.

\begin{tabular}{|cc|}
\hline Años & Número de asuntos \\
\hline 1959 & 51.573 \\
1960 & 49.865 \\
1961 & 44.862 \\
1962 & 43.929 \\
1963 & 54.981 \\
1964 & 58.339 \\
1965 & 63.784 \\
1966 & 68.914 \\
1967 & 86.233 \\
1968 & 95.744 \\
1969 & 87.235 \\
1970 & 121.555 \\
\hline
\end{tabular}

\subsubsection{Período 1970 a 1980}

Este período ha sido estudiado también por Toharia Cortés, en su obra «iPleitos tengas!...Introducción a la cultura legal española». ${ }^{23}$

Advierte, de entrada, este autor que el volumen de litigiosidad civil creció sustancialmente a lo largo de la década 1970-1980.

Ilustra esa situación la siguiente tabla, que refleja los asuntos ingresados en los juzgados de primera instancia y la tasa de tales asuntos por 1.000 habitantes. ${ }^{24}$ Como hice notar en el apartado 1 anterior, estos números han de ser corregidos al alza para incluir los asuntos de los juzgados municipales y comarcales.

22 M. Roig Alonso, Economía de la Justicia (Un primer análisis del caso español), Facultat de Ciències Económiques i Empresarials, Universitat de València, Quaderns de treball, número 15 , abril, 1988 , cuadro número 2 .

23 Editada en Madrid, 1987. Salvo expresa advertencia en sentido diferente, en el texto se hace una selección y resumen de sus contenidos importantes para este informe.

24 Tabla procedente de J.J. Toharia Cortés, “i Pleitos tengas!.”. Introducción a la cultura legal española, Madrid, 1987, p. 76. 


\begin{tabular}{|c|c|c|}
\hline Año & $\begin{array}{l}\text { Número total } \\
\text { asuntos }\end{array}$ & $\begin{array}{l}\text { Tasa por mil } \\
\text { habitantes }\end{array}$ \\
\hline 1970 & 78.448 & 2,32 \\
\hline 1971 & 84.960 & 2,50 \\
\hline 1972 & 78.660 & 2,29 \\
\hline 1973 & 75.984 & 2,19 \\
\hline 1974 & 93.400 & 2,66 \\
\hline 1975 & 107.648 & 3,03 \\
\hline 1976 & 114.328 & 3,18 \\
\hline 1977 & 128.530 & 3,55 \\
\hline 1978 & 145.933 & 3,98 \\
\hline 1979 & 150.290 & 4,06 \\
\hline 1980 & 183.333 & 4,92 \\
\hline
\end{tabular}

La actividad jurídica no judicial, medida por el indicador de los instrumentos notariales autorizados, también ha tenido un crecimiento muy importante, como puede apreciarse en la tabla siguiente. ${ }^{25}$

\begin{tabular}{|ccc|}
\hline Año & Número total & $\begin{array}{c}\text { Tasa por mil } \\
\text { habitantes }\end{array}$ \\
\hline 1970 & 4.806 .547 & 142,1 \\
1971 & 4.791 .404 & 140,6 \\
1972 & 4.426 .506 & 128,8 \\
1973 & 4.734 .047 & 136,5 \\
1974 & 5.632 .583 & 160,8 \\
1975 & 6.027 .483 & 169,9 \\
1976 & 6.217 .039 & 173,5 \\
1977 & 6.904 .581 & 190,4 \\
1978 & 7.217 .164 & 196,8 \\
1979 & 7.770 .089 & 209,4 \\
1980 & 8.391 .130 & 225,1 \\
\hline
\end{tabular}

25 Tabla procedente de J.J. Toharia, "; Pleitos tengas!.". Introducción a la cultura legal española, Madrid, 1987, p. 78. 
Toharia destaca que, a diferencia de la que había sido la tendencia hasta 1970, el porcentaje de incremento de los indicadores de la litigiosidad civil ha sido muy superior al de los indicadores de la actividad jurídica no judicial (entre 1970 y 1980 los primeros crecieron un 134 por ciento, mientras que los segundos sólo lo hicieron en un 75 por ciento), lo que le permite concluir que el volumen neto de la litigiosidad civil ha aumentado sustancialmente en España en el período considerado.

La composición cualitativa de esa litigiosidad mantiene la tendencia mostrada en el período anterior. Los asuntos tramitados por el proceso ordinario más complejo (asuntos de mayor valor económico), por el ordinario menos complejo (valor económico inferior) y por el proceso sumario para reclamar deudas de dinero que consten en una documentación específica (el llamado juicio ejecutivo) suponían, en 1970, el 74,3 por ciento de los asuntos ingresados en los juzgados de primera instancia; en 1975 ascendieron al 82,3 por ciento; en 1980 constituían el 80,9 por ciento.

Los asuntos en materia de Derecho del Trabajo y de la Seguridad Social experimentaron también un fuerte crecimiento en este período, como puede observarse en la tabla siguiente que refleja los asuntos ingresados en los tribunales unipersonales de primera instancia. ${ }^{26}$

\begin{tabular}{|cc|}
\hline Año & $\begin{array}{c}\text { Número de } \\
\text { asuntos ingresados }\end{array}$ \\
\hline 1970 & 121.555 \\
1971 & 135.074 \\
1972 & 131.518 \\
1973 & 126.390 \\
1974 & 157.340 \\
1975 & 192.838 \\
1976 & 259.306 \\
1977 & 291.909 \\
1978 & 385.219 \\
1979 & 428.913 \\
1980 & 270.002 \\
\hline
\end{tabular}

26 M. Roig Alonso, Economía de la Justicia (Un primer análisis del caso español), Facultat de Ciències Económiques i Empresarials, Universitat de València, Quaderns de treball, número 15 , abril, 1988 , cuadro número 2 . 


\subsubsection{Años posteriores a 1980}

El estudio más actualizado es el que presenta Pastor Prieto en su obra "iAh de la justicia! Política judicial y economía». ${ }^{27}$

El siguiente cuadro refleja el número global de asuntos presentados ante los tribunales civiles de primera instancia en los años desde 1983 a $1990 . .^{28}$

\begin{tabular}{|c|c|}
\hline Años & Número de asuntos \\
\hline 1983 & 397.070 \\
1984 & 400.575 \\
1985 & 396.982 \\
1986 & 395.436 \\
1987 & 414.123 \\
1988 & 432.999 \\
1989 & 435.517 \\
1990 & 548.414 \\
\hline
\end{tabular}

Para la correcta interpretación de la tabla anterior hay que tener en cuenta que: $1^{\circ}$ ) se incluyen los asuntos presentados ante los juzgados de distrito, mientras que en las cifras de los anteriores apartados 1 y 2 no se incluyeron, por no disponer de las mismas, las cifras de asuntos ante los juzgados municipales y comarcales (anterior denominación de los juzgados de distrito); 2o) desde 1981 los asuntos de separación matrimonial y divorcio experimentaron un importante incremento, por la profunda modificación del Derecho Matrimonial español.

Para la composición cualitativa de la litigiosidad civil el estudio citado de Pastor Prieto ofrece cifras de 1986, separando las correspondientes a los juzgados de primera instancia y las de los juzgados de distrito. Hasta 1989 la competencia para conocer de la primera instancia de las materias civiles estaba distribuida entre esas dos clases de tribunales. En 1989 los juzgados de distrito fueron transformados en juzgados de primera instancia, de modo que la competencia sobre

27 Editada en Madrid, 1993. Salvo expresa advertencia el apartado C del texto es un resumen de lo más importante de la obra citada, que tiene interés para este informe.

28 Elaborado a partir de la tabla que recoge S. Pastor Prieto, ;Ah de la justicia! Política judicial y economia, Madrid, 1993, p. 74. 
materias civiles en la primera instancia corresponde a una sola clase de tribunal.

Las dos siguientes tablas ilustran sobre el porcentaje de las diferentes clases de asuntos ante los juzgados de primera instancia, con referencia al año 1986.

La primera se refiere a la clase de procedimiento que ha seguido el asunto. $^{29}$

\begin{tabular}{|ll|}
\hline Clase de procedimiento & $\%$ \\
\hline Ordinario mayor cuantía & 1,5 \\
Ordinario menor cuantía & 13,8 \\
Ejecutivo (sumario documental) & 54,9 \\
Ejecución hipotecaria especial & 7,0 \\
Protección derechos Registro Propiedad & 0,3 \\
Arrendamientos urbanos & 1,8 \\
Arrendamientos rústicos & 0,2 \\
Herencias & 0,5 \\
Insolvencias & 2,3 \\
Incidentes & 0,9 \\
Protección sumaria de la posesión & 1,5 \\
Retractos & 0,2 \\
Justicia gratuita & 4,5 \\
Otros & 11,1 \\
\hline
\end{tabular}

La segunda tabla ilustra sobre las clases de asuntos según su valor económico. ${ }^{30}$

\begin{tabular}{|ll|}
\hline Valor en pesetas & $\%$ \\
\hline Hasta 100.000 & 11,1 \\
De 100.000 a 150.000 & 15,3 \\
De 150.001 a 500.000 & 25,5 \\
Más de 500.000 & 30,5 \\
Cuantía no estimable & 7,7 \\
No consta determinación sobre cuantía & 9,9 \\
\hline
\end{tabular}

29 Elaborado a partir de la tabla que recoge S. Pastor Prieto, ;Ah de la justicia! Política judicial y economia, Madrid, 1993, p. 79.

30 Elaborado a partir de la tabla que recoge S. Pastor Prieto, $;$ Ah de la justicia! Politica judicial y economia, Madrid, 1993, p. 79. 
La siguiente tabla refleja la composición cualitativa de la demanda de tutela judicial a los juzgados de distrito en $1986 .{ }^{31}$

\begin{tabular}{|lrr|}
\hline Clase de asunto & Número de asuntos & $\%$ \\
\hline Acto de conciliación & 25.817 & 14,9 \\
Juicio verbal & 35.127 & 20,3 \\
Juicio de cognición & 57.629 & 33,2 \\
Arrendamientos urbanos & 54.151 & 31,2 \\
Arrendamientos rústicos & 1.004 & 0,6 \\
\hline
\end{tabular}

Con referencia a los tribunales especiales de trabajo, que en 1988 fueron transformados en tribunales especializados dentro de la organización judicial única, el siguiente cuadro informa del número de asuntos presentados en primera instancia. ${ }^{32}$

\begin{tabular}{|cc|}
\hline Año & Número de asuntos \\
\hline 1981 & 300.000 \\
1982 & 286.000 \\
1983 & 340.000 \\
1984 & 348.000 \\
1985 & 295.000 \\
1986 & 267.000 \\
1987 & 268.000 \\
1988 & 265.000 \\
1989 & 267.000 \\
1990 & 277.000 \\
\hline
\end{tabular}

31 Tabla elaborada por S. Pastor Prieto, iAh de la justicia! Política judicial y economia, Madrid, 1993, p. 80.

32 Elaborado a partir de la tabla que recoge S. Pastor Prieto, ${ }_{i}$ Ah de La justicia! Política judicial y economia, Madrid, 1993, p. 103. 


\section{Breve descripción de la litigiosidad civil en el momento presente}

\subsection{Número de asuntos ingresados y resueltos}

Los datos más recientes disponibles son los que ofrece la Memoria del Consejo General del Poder Judicial de 1997, que van referidos a 1996, pero que consideran frecuentemente, a efectos comparativos, los cuatro años anteriores.

En este informe recogeremos, salvo especial indicación, los cuadros en los que se especifican los asuntos pendientes a principio de año, los ingresados en el año, los resueltos en el año y los pendientes a fin de año.

Los cuadros se refieren a la actividad de diversas clases de tribunales competentes en materia civil en sentido amplio. En algunos de estos tribunales los asuntos son, total o principalmente, recursos; en otros, total o principalmente asuntos en primera instancia. La anterior circunstancia se indicará, respectivamente, con las expresiones "recursos" y "primera instancia», entre paréntesis, junto al nombre del tribunal.

\subsubsection{Juzgados de Primera Instancia}

La siguiente tabla refleja los asuntos ingresados en los juzgados de primera instancia en los años 1992-1996 y el porcentaje de evolución del último año sobre el primero del quinquenio. ${ }^{33}$

\begin{tabular}{|lllllll|}
\hline Años & 1992 & 1993 & 1994 & 1995 & 1996 & \% evolución \\
\hline Asuntos & 606.697 & 681.760 & 673.730 & 636.652 & 601.418 & $-0,87$ \\
\hline
\end{tabular}

El siguiente cuadro refleja el número de asuntos ingresados en los juzgados de primera instancia especializados en materia de familia (primera instancia). ${ }^{34}$

33 Elaborada a partir del cuadro recogido en Consejo General del Poder Judicial, Memoria que el Consejo general del Poder Judicial eleva a las Cortes Generales, Madrid, 1997, p. 263.

34 Elaborado a partir del cuadro recogido en Consejo General Poder Judicial, Memoria que el Consejo general del Poder Judicial eleva a las Cortes Generales, Madrid, 1997, p. 269. 


\begin{tabular}{|ccccccc|}
\hline Años & 1992 & 1993 & 1994 & 1995 & 1996 & $\begin{array}{c}\% \text { evolución } \\
1992-1996\end{array}$ \\
\hline Asuntos & 66.777 & 72.423 & 79.161 & 82.580 & 83.990 & 25,78 \\
\hline
\end{tabular}

2.1.2 Juzgados de lo social (primera instancia; materia civil en sentido amplio - Derecho del Trabajo y de la Seguridad Social- )

El siguiente cuadro se refiere sólo a los asuntos del año $1996 .^{35}$

\begin{tabular}{|llllll|}
\hline & $\begin{array}{l}\text { Pendiente } \\
\text { Inicio año }\end{array}$ & $\begin{array}{l}\text { Ingresado } \\
\text { en año }\end{array}$ & Resuelto & $\begin{array}{l}\text { Pendiente } \\
\text { fin año }\end{array}$ & Sentencias \\
\hline $\begin{array}{l}\text { Número } \\
\text { asuntos }\end{array}$ & 90.233 & 261.140 & 267.917 & 83.456 & 164.331 \\
\hline
\end{tabular}

Se hace notar la desagregación (que falta en los datos del anterior apartado 1) entre "asuntos resueltos" y "sentencias", que pone de manifiesto el número de asuntos que se terminan mediante conciliación ante el Juzgado de lo Social o por desistimiento.

\subsubsection{Audiencias provinciales (recursos) ${ }^{36}$}

\begin{tabular}{|c|c|c|c|c|}
\hline \multirow[t]{2}{*}{ Año } & \multicolumn{4}{|c|}{ Asuntos } \\
\hline & $\begin{array}{l}\text { Pendientes al } \\
\text { inicio del año }\end{array}$ & $\begin{array}{l}\text { Iniciados } \\
\text { en el año }\end{array}$ & $\begin{array}{l}\text { Resueltos } \\
\text { en el año }\end{array}$ & $\begin{array}{l}\text { Pendientes al } \\
\text { finalizar el afio }\end{array}$ \\
\hline 1992 & 50767 & 82328 & 79188 & 53907 \\
\hline 1993 & 53907 & 86803 & 86327 & 54383 \\
\hline 1994 & 54383 & 96202 & 87871 & 62714 \\
\hline 1995 & 62714 & 101882 & 89280 & 75316 \\
\hline 1996 & 75316 & 115258 & 102750 & 87824 \\
\hline
\end{tabular}

35 Elaborado a partir del cuadro recogido en Consejo General del Poder Judicial, Memoria que el Consejo general del Poder Judicial eleva a las Cortes Generales, Madrid, 1997, p. 281.

36 Consejo General del Poder Judicial, Memoria que el Consejo general del Poder judicial eleva a las Cortes Generales, Madrid, 1997, p. 259. 
2.1.4 Tribunales superiores de justicia

a) Salas de lo civil (recursos) ${ }^{37}$

\begin{tabular}{|l|cccc|}
\hline \multirow{2}{*}{ Año } & \multicolumn{4}{|c|}{ Asuntos } \\
\cline { 2 - 5 } & $\begin{array}{c}\text { Pendientes a } \\
\text { inicio del año }\end{array}$ & $\begin{array}{l}\text { Iniciados } \\
\text { en el año }\end{array}$ & $\begin{array}{c}\text { Resueltos } \\
\text { en el año }\end{array}$ & $\begin{array}{c}\text { Pendientes a } \\
\text { final de año }\end{array}$ \\
\hline 1992 & 26 & 54 & 60 & 20 \\
1993 & 20 & 99 & 84 & 35 \\
1994 & 35 & 108 & 92 & 51 \\
1995 & 51 & 133 & 136 & 48 \\
1996 & 48 & 136 & 135 & 49 \\
\hline
\end{tabular}

b) Salas de lo social (recursos; materia civil en sentido amplio Derecho del trabajo y de la Seguridad Social-) ${ }^{38}$

\begin{tabular}{|l|cccc|}
\hline \multirow{2}{*}{ Año } & \multicolumn{4}{|c|}{ Asuntos } \\
\cline { 2 - 5 } & $\begin{array}{c}\text { Pendientes a } \\
\text { inicio del año }\end{array}$ & $\begin{array}{l}\text { Iniciados } \\
\text { en el año }\end{array}$ & $\begin{array}{c}\text { Resueltos } \\
\text { en el año }\end{array}$ & $\begin{array}{c}\text { Pendientes a } \\
\text { final de año }\end{array}$ \\
\hline 1992 & 28621 & 46875 & 42302 & 33194 \\
1993 & 33194 & 49762 & 44369 & 38587 \\
1994 & 38587 & 53484 & 47964 & 44123 \\
1995 & 44123 & 55839 & 48610 & 51352 \\
1996 & 51352 & 57577 & 54930 & 53999 \\
\hline
\end{tabular}

37 Consejo General del Poder Judicial, Memoria que el Consejo general del Poder Judicial eleva a las Cortes Generales, Madrid, 1997, p. 234.

38 Consejo General del Poder Judicial, Memoria que el Consejo general del Poder Judicial eleva a las Cortes Generales, Madrid, 1997, p. 248. 


\subsubsection{Tribunal Supremo}

a) Sala de lo Civil (recursos) ${ }^{39}$

\begin{tabular}{|l|llll|}
\hline \multirow{2}{*}{ Año } & \multicolumn{4}{|c|}{ Asuntos } \\
\cline { 2 - 5 } & $\begin{array}{l}\text { Pendientes a } \\
\text { inicio del año }\end{array}$ & $\begin{array}{l}\text { Iniciados } \\
\text { en el año }\end{array}$ & $\begin{array}{c}\text { Resueltos } \\
\text { en el año }\end{array}$ & $\begin{array}{l}\text { Pendientes a } \\
\text { final de año }\end{array}$ \\
\hline 1992 & 5510 & 4016 & 2795 & 6731 \\
1993 & 6731 & 3324 & 3464 & 6591 \\
1994 & 6591 & 3660 & 3905 & 6346 \\
1995 & 6346 & 3782 & 2902 & 7226 \\
1996 & 7226 & 3989 & 3118 & 8097 \\
\hline
\end{tabular}

b) Sala de lo social (recursos; materia civil en sentido amplio -Derecho del Trabajo y de la Seguridad Social- ${ }^{40}$

\begin{tabular}{|l|llll|}
\hline \multirow{2}{*}{ Año } & \multicolumn{4}{|c|}{ Asuntos } \\
\cline { 2 - 5 } & $\begin{array}{l}\text { Pendientes a } \\
\text { inicio del año }\end{array}$ & $\begin{array}{l}\text { Iniciados } \\
\text { en año }\end{array}$ & $\begin{array}{c}\text { Resueltos } \\
\text { en el año }\end{array}$ & $\begin{array}{l}\text { Pendientes a } \\
\text { final de año }\end{array}$ \\
\hline 1992 & 1790 & 4168 & 2502 & 3456 \\
1993 & 3456 & 3733 & 3368 & 3821 \\
1994 & 3821 & 4025 & 4191 & 3655 \\
1995 & 3655 & 4120 & 4452 & 3323 \\
1996 & 3323 & 4672 & 4592 & 3403 \\
\hline
\end{tabular}

39 Consejo General del Poder Judicial, Memoria que el Consejo general del Poder Judicial eleva a las Cortes Generales, Madrid, 1997, p. 213.

40 Consejo General del Poder Judicial, Memoria que el Consejo general del Poder Judicial eleva a las Cortes Generales, Madrid, 1997, p. 215. 


\subsection{Tendencias recientes en la composición cualitativa de la litigiosidad civil}

Las estadísticas que ofrece la Memoria del Consejo General del Poder Judicial no desagregan las clases de asuntos civiles, más allá de los de familia tramitados por juzgados especializados y de los asuntos laborales, que hemos considerado civiles en sentido amplio.

A partir de algunos datos de esa estadística y de la información que proporciona Pastor Prieto ${ }^{41}$ se puede establecer la conclusión, de valor sólo aproximativo, de que la litigiosidad civil (en sentido amplio) se centra, principalmente, en las siguientes clases de asuntos: litigios laborales y de seguridad social, reclamaciones de deudas que constan en documentos específicos y pueden acceder a un procedimiento declarativo facilitado, litigios por ruptura matrimonial y litigios en materia de arrendamientos urbanos.

No es posible conocer las materias sobre las que versan los procesos que se tramitan por vía ordinaria, así como tampoco la frecuencia con la que se solicitan medidas cautelares en relación con un proceso principal.

\section{Descripción de la formación jurídica en España}

\subsection{Formación jurídica impartida por la Universidad}

3.1.1 y 3.1.2 Número de facultades de Derecho en España. Públicas y privadas.

$\mathrm{La}$ información relevante se presenta sintéticamente en el siguiente cuadro. $^{42}$ 85.

41 S. Pastor Prieto, ;Ah de la justicia! Politica judicial y economia, Madrid, 1993, pp. $72-$

42 Fuente: datos del Anuario El País 1998, p. 117, a partir de datos del Instituto Nacional de Estadística 1997. 
Número de facultades de Derecho de universidades públicas (o adscritas a universidades públicas)

Número de facultades de Derecho de universidades privadas

Total de facultades de Derecho

3.1.3 Otros centros universitarios que preparan para profesiones jurídicas

Entendiendo que la referencia se hace a la preparación para profesiones jurídicas que se ocupan de materias civiles en sentido amplio, han de mencionarse las escuelas universitarias de Relaciones Laborales, que gestionan los estudios conducentes a la obtención del título universitario de Diplomado en Relaciones Laborales, con el que se puede acceder al ejercicio de la profesión de graduado social (antigua denominación académica y de más frecuente uso para designar la actividad profesional), cuyas funciones se expusieron en el apartado I.1.

El número de escuelas universitarias de Relaciones Laborales dependientes de universidades públicas es de 52 .

3.1.4 Número de estudiantes matriculados en facultades de Derecho

La siguiente tabla presenta el número de estudiantes matriculados en el curso 1996-1997 y el número de plazas disponibles para ingreso en el curso 1998-1999 (excluidas universidades privadas cuyo numerus clausus no está regulado), tanto en las facultades de Derecho, como en las escuelas universitarias de Relaciones Laborales ${ }^{43}$.

\begin{tabular}{|lcc|}
\hline & Número de matriculados & Número de plazas dispo- \\
& $1996-97$ & nibles ingreso 1998-99 \\
\hline Facultad de Derecho & 199.814 & 30.414 \\
E. U. Relaciones Laborales & 59.455 & 14.007 \\
\hline
\end{tabular}

43 Elaborado a partir de la información que proporciona el Anuario El País 1998, p. 117, con base en de datos del Instituto Nacional de Estadística 1997, y de información que figura en la web del Consejo de Universidades. 
3.1.5 Número de estudiantes que, al finalizar los estudios universitarios, preparan el acceso a centros de preparación profesional para adquirir la condición de juez, de abogado o equivalente.

3.1.5.1 Para acceder a la carrera judicial se requiere superar un procedimiento selectivo que se expondrá con más detalle en el siguiente apartado 3.2.1.

Como cifra más aproximada al dato que se indica en el epígrafe del precedente apartado 5, presento en la tabla siguiente los datos más relevantes de los participantes en el procedimiento selectivo convocado por acuerdo del Consejo General del Poder Judicial de 17 de mayo de $1995 .{ }^{44}$

\begin{tabular}{|c|c|}
\hline Solicitudes presentadas & 5.692 \\
\hline Presentados a la $1^{a}$ prueba & 4.457 \\
\hline Aprobados en la $1^{\mathbf{a}}$ prueba & 663 \\
\hline Presentados a la $2^{\mathrm{a}}$ prueba & 661 \\
\hline Aprobados en la $2^{\mathrm{a}}$ prueba & 222 \\
\hline Presentados a la $3^{a}$ prueba & 222 \\
\hline Aprobados finalmente & 187 \\
\hline
\end{tabular}

Es útil advertir, complementariamente, que de los 187 aprobados, 108 eran mujeres $(57,75 \%)$ y 79 varones $(42,25 \%)$.

3.1.5.2 Para acceder a la condición de abogado no es preceptivo realizar una formación profesional específica (véase más ampliamente el siguiente apartado 3.2), de modo que no es posible dar respuesta a la cuestión que se formula.

De modo aproximativo cabe apuntar que, en buena medida por la facilidad del acceso al ejercicio de la profesión de abogado, un buen número de licenciados en Derecho proyectan dedicarse a esa actividad profesional. Cosa distinta es cuántos de ellos consiguen consolidarse en el ejercicio.

Notas previas a las cuestiones de los apartados 6 al 9. Ordenación de los estudios de Licenciado en Derecho en España. 
Como puede incidir en los temas que han de tratarse en los siguientes apartados 6 al 9, informo a continuación de las características más destacadas de la ordenación jurídica de los estudios universitarios en general y de los conducentes al título de Licenciado en Derecho en especial.

A) La ley de Reforma Universitaria de 1983 ha reestructurado la Universidad española y la enseñanza superior en España. La reforma ha afectado a la ordenación académica de las enseñanzas.

B) Los títulos universitarios -entre ellos el de Licenciado en Derechopueden obtenerse tras superar los estudios realizados según un plan de estudios que elabora y aprueba cada Universidad, con sujeción a las directrices previamente establecidas por el Gobierno. Esta sujeción se comprueba mediante la competencia de homologación que tiene atribuida el Consejo de Universidades.

C) Las directrices generales para la licenciatura en Derecho -en parte comunes a todos los planes, en parte propias de esa titulación- consisten principalmente en lo siguiente:

a) Los planes de estudios conducentes a esa titulación han de ordenar las enseñanzas en dos ciclos (no hay, en consecuencia, título al finalizar el primer ciclo), con una duración de al menos dos años por ciclo y de al menos cuatro por ambos.

b) La carga lectiva global del plan de estudios no puede ser inferior a trescientos créditos, ni superior a trescientos cuarenta y cinco créditos. Crédito es la unidad de valoración de las enseñanzas. Un crédito corresponde a diez horas de docencia teórica, práctica o equivalente (como tal pueden ser consideradas actividades académicas dirigidas).

c) El plan de estudios está integrado por unas materias troncales, obligatorias en todas las universidades, determinadas por el Gobierno al establecer las directrices generales propias de cada titulación, y que han de suponer como mínimo el 55\% de los créditos del plan; unas materias establecidas discrecionalmente por cada universidad, sea con el carácter de obligatorias, sea con el de optativas; en fin, por unas materias de libre elección por el estudiante, que han de suponer como mínimo el $10 \%$ de los créditos del plan. 
3.1.6 Duración de los estudios para obtener el título de Licenciado en Derecho

Según la ordenación jurídica de los mismos, han de tener una duración mínima de cuatro años. Los planes de estudios aprobados prevén duraciones de cuatro años y de cuatro años y medio.

Sobre la duración real de los estudios -años que un número significativo de estudiantes necesita para terminar los estudios- se carece de datos contrastados, por el escaso tiempo de implantación de los nuevos planes. De modo aproximativo puede decirse que sólo un número muy reducido de estudiantes de las primeras promociones ha conseguido terminar los estudios en los años previstos por el plan.

3.1.7 Materias comprendidas en los planes de estudio de la licenciatura en Derecho

3.1.7.1 Materias jurídicas. Derecho positivo y Derecho comparado

El contenido fundamental de los planes de estudio -tanto de los actuales, como de los dos planes uniformes que regían antes de la reforma- son materias del Derecho positivo vigente en España: derechos administrativo, constitucional, civil, mercantil, procesal, internacional público y privado, penal, de las comunidades europeas, del trabajo y de la protección social, tributario y de las finanzas públicas.

El Derecho comparado no forma parte de las materias obligatorias en todas las universidades, pero la materia «Teoría del Derecho» introduce una comprensión no positivo-estatal del fenómeno jurídico y en la didáctica de las diferentes materias se utilizan referencias a ordenamientos jurídicos extranjeros.

La disposición que establece las directrices generales propias del título de Licenciado en Derecho recomienda incluir el Derecho comparado como materia obligatoria de Universidad o como materia optativa. Algunas universidades la han incluido como asignatura optativa.

3.1.7.2 Materias no jurídicas: materias sociales y económicas; materias instrumentales

Están comprendidas en los planes de estudio, pero es importante matizar con qué grado de obligatoriedad. 
a) Como materias obligatorias en todas las universidades.

Con un nivel básico o de introducción son materias obligatorias en todas las universidades la historia del Derecho, la filosofía del Derecho y la economía.

La disposición reguladora de las directrices propias del título de Licenciado en Derecho recomienda introducir como materia obligatoria de Universidad o como materia optativa, materias del campo de las ciencias sociales -como la sociología y otras- y materias instrumentales -como la contabilidad y la informática-.

b) Como materias obligatorias en los planes de cada universidad Algunas universidades -aunque no la mayoría de ellas- han incluido como materias obligatorias en su plan de estudios materias como informática, una lengua extranjera (inglés, francés, alemán) y humanidades.

c) Como materias optativas

La mayor parte de universidades ha incluido como materias optativas una amplia gama de materias no jurídicas: informática, sociología, profundización en economía, deontología, profundización en historia jurídica, de las ideas políticas, del proceso de unificación europea.

A esta oferta ha de añadirse la que supone el 10 por ciento de créditos de libre configuración, que pueden aplicarse a materias no comprendidas en el plan de estudios de la licenciatura y, por lo tanto, posibilitan un importante complemento de formación no estrictamente jurídica.

3.1.7.3 Materias de arbitraje, ADR, ética e informática aplicada al Derecho

Está comprendida como obligatoria en los planes de estudio de todas las universidades una formación de tipo básico en materias de arbitraje y ADR, aunque la última limitada al estudio de los supuestos de mediación y conciliación específicamente regulados por el Derecho estatal.

Una formación profunda en estas materias y la inclusión de materias como ética e informática se produce en calidad de materia obligatoria de Universidad (pocos casos) o como materia optativa (la mayor parte de los planes de estudio). 
3.1.8 Enseñanzas generales y enseñanzas especializadas. Momento de los estudios en el que se introducen las enseñanzas especializadas.

3.1.8.1 Son enseñanzas generales -en el sentido de obligatorias para todos los estudiantes de Derecho- las que se han enunciado en los anteriores apartados. La docencia de las mismas supone aproximadamente el 55 por ciento de toda la docencia del plan de estudios.

Están ordenadas en dos ciclos de dos años: el primer ciclo comprende principalmente materias básicas e introducción a materias; el segundo ciclo comprende profundización en materias comunes y materias comunes nuevas que precisan una base de formación jurídica.

3.1.8.2 Las enseñanzas especializadas consisten en la profundización en áreas específicas de materias jurídicas (por ejemplo: Derecho inmobiliario, internacional económico, de la competencia y de la propiedad industrial, derechos fundamentales, organizaciones internacionales, justicia constitucional, Derecho bancario y bursátil, Derecho de la prueba, de la tutela judicial cautelar, etc.) y en materias económicas principalmente relacionadas con el sector privado. La segunda orientación de la especialización suele ser el complemento más apreciado de la formación jurídica general.

3.1.8.3 Momento en el que se introducen las enseñanzas especializadas

Sin perjuicio de lo que se dirá en el siguiente apartado 9, ha de indicarse que la mayor parte de los planes de estudio introducen las enseñanzas especializadas a partir del segundo cuatrimestre del año académico, o a partir del segundo año académico.

La ordenación de una lógica secuencia de estudios -primero: lo general y básico; a continuación, lo especial- se realiza mediante reglas obligatorias o mediante recomendaciones de incompatibilidad en función de las especificas materias a cursar -por ejemplo: para cursar Derecho concursal es necesario haber superado Derecho mercantil y Derecho procesal civil-.

3.1.9 Contenido de la especialización que se ofrece en los planes de estudio de la Licenciatura en Derecho

El plan de estudios de 1965 -que era el plan de estudios más modernizado de los dos que regían en todas las universidades antes de la 
reforma que supuso la diversificación de los planes- establecía la especialización en los cursos $4^{\circ}$ y $5^{\circ}$ (los dos últimos) de la licenciatura. Se establecían tres especialidades: Derecho público, Derecho privado, Derecho de la empresa.

Con los nuevos planes de estudio es necesario distinguir entre especialización dirigida y no dirigida.

Las universidades privadas han optado principalmente por la primera. Ofrecen estudios de licenciatura en Derecho con diplomas complementarios en Derecho Comunitario o Estudios Empresariales o de especialización económica. Tales diplomas no tienen la misma validez oficial que el título de Licenciado, pero optan a ser valoradas en el mercado de los servicios jurídicos. Para obtener el diploma se requiere cursar una serie determinada de materias lo que, normalmente, también supone una duración de los estudios mayor que la prevista para la licenciatura.

La mayor parte de universidades tienen previsto un tipo de especialización que puede ser configurada por el propio estudiante, mediante la elección de un conjunto coherente de materias optativas y de libre configuración. Para ayudar en la elección algunas universidades establecen "itinerarios orientativos" para que las materias optativas puedan ser elegidas en función de diversas salidas profesionales posibles para un licenciado en Derecho.

\subsubsection{Métodos de enseñanza}

3.1.10.1 Número de alumnos por grupo. Espacio físico de la docencia. Incidencia en los métodos de trabajo

Hay que distinguir la docencia teórica y la docencia práctica.

La docencia teórica se imparte a grupos de tamaño distinto según las universidades, pero cuya media puede situarse en 100 estudiantes, que ocupan aulas de tamaño mediano. Eso induce una técnica docente en la que prepondera la exposición de temas por el profesor, con ayuda -en ocasiones- de proyección de transparencias y con posibilidad de un dialogo limitado profesor-estudiante con finalidad de aclaración de la exposición. Las sesiones se desarrollan con arreglo a un programa de temas, complementado con referencias bibliográficas generales accesibles.

La docencia práctica se imparte a grupos de tamaño distinto según universidades, pero cuya media ronda los 35 alumnos, que son acogi- 
dos en aulas pequeñas. En el siguiente apartado se exponen los diversos contenidos y métodos de la docencia práctica.

\subsubsection{Docencia mediante actividades académicas dirigidas}

La disposición que rige las directrices comunes de todos los planes de estudio para títulos universitarios autoriza que los planes de estudios prevean que parte de los créditos -el 30 por ciento-correspondientes a la docencia teórica y práctica de toda clase de materias, sean obtenidos mediante actividades académicas dirigidas. Por otra parte la disposición de directrices propias del título de Derecho establece como materia obligatoria en todas las universidades el llamado "Practicum»-introducción a la práctica integrada del Derecho-, con un mínimo de docencia de 14 créditos, todos los cuales han de ser obtenidos mediante trabajos académicamente dirigidos y mediante prácticas en instituciones públicas y privadas controladas académicamente. Véase la ampliación de información en el siguiente apartado 3.1.10.3 b.

3.1.10.3 Métodos de aprendizaje que requieren principalmente una actitud activa del estudiante

En los métodos de docencia que se aplican para la obtención de créditos teóricos sigue predominando el de exposición de temas por el profesor, con utilización de técnicas audiovisuales elementales para facilitar la comprensión de conjunto del tema y permitiendo un diálogo profesor-estudiante suficiente para posibilitar las aclaraciones convenientes sobre la exposición.

Las mayores innovaciones en los métodos de docencia se han producido en la docencia práctica, que ha sido muy porenciada por los nuevos planes de estudios. La disposición reguladora de las directrices propias del título de Licenciado en Derecho establecen como obligatorio un mínimo de créditos prácticos por materia -entre un 15 y un 20 por ciento de los asignados a la materia-, y también establecen como obligatoria en todos los planes de estudio de Derecho la materia de "Practicum»-introducción a la práctica integrada del Derecho- con un mínimo de 14 créditos.

a) Contenido y métodos de trabajo en los créditos prácticos

Presentan gran variedad, pero pueden enumerarse sin exhaustividad los siguientes: aprendizaje del uso de bibliografía jurídica, de las fuen- 
tes de conocimiento de las normas, de las colecciones de doctrina jurisprudencial; realización de trabajos sencillos sobre temas jurídicos, aprendizaje y aplicación de técnicas de tratamiento de casos jurídicos, solución de casos prácticos ideales, análisis de noticias jurídicas de los medios de comunicación, preparación de actos jurídicos escritos, comentarios sobre resoluciones judiciales, elaboración de los distintos actos de desarrollo de un procedimiento judicial asignando los diferentes roles de los sujetos del proceso a pequeños grupos de alumnos.

b) «Practicum».

Esta materia obligatoria en los planes de estudio de Derecho de todas las universidades puede tener en cada una de ellas algunas diferencias.

Expongo, a continuación, los aspectos generales del "Practicum» de Derecho en la Universidad de Valencia.

Pueden acceder al mismo los estudiantes que se encuentren en una etapa avanzada de sus estudios de licenciatura.

Sus objetivos son completar la formación del estudiante mediante la realización de un periodo de prácticas en entidades privadas o públicas, con la finalidad de que conozca la vida profesional, de introducirle en la problemática jurídica de la entidad, de que contraste los conocimientos teóricos y prácticos adquiridos con la experiencia real, de que realice trabajos que pongan a prueba la capacidad crítica y reflexiva del estudiante, sus aptitudes para la toma de decisiones y para analizar problemas jurídicos reales.

Su duración es de un trimestre con jornada ordinaria laboral, lo que supone aproximadamente 490 horas de prácticas.

Las prácticas se desarrollan bajo la supervisión de un tutor designado por la entidad en que se desarrollan las prácticas y de un tutor académico -encargado del seguimiento y evaluación- y consisten en participar en las actividades ordinarias que se realizan en las siguientes entidades: administración local, autonómica e institucional; empresas privadas; despachos de abogados y de procuradores; notarías y registros de la propiedad; consultorías y asesorías de empresas; juzgados y tribunales.

Al término del «Practicum» el estudiante ha de elaborar una memoria sobre la actividad realizada.

3.1.10.4 Uso de técnicas audiovisuales y de tecnología informática

En pocas universidades están incorporadas a la infraestructura del aula técnicas como las siguientes: ordenador personal con las aplicacio- 
nes adecuadas, proyector de cuerpos opacos y de transparencias, proyector de diapositivas y videoproyector.

En algunas universidades existen aulas informáticas desde cuyas terminales los estudiantes tienen acceso -temporalmente limitado- a Internet y al servicio de correo electrónico.

En un mayor número de universidades se utilizan en el aula proyectores de transparencias y de diapositivas y los estudiantes disponen de terminales informáticas para consultas en bases de datos disponibles en la red de la universidad y para realizar gestiones administrativas de matriculación y de consulta de su expediente académico.

3.1.11 Efectos de la mundialización sobre los programas de enseñanza y sobre los métodos de trabajo

La incidencia sobre la utilización de medios instrumentales facilitados por las nuevas tecnologías en el aprendizaje y en la práctica jurídica se expuso en el anterior apartado 10.2. En síntesis puede decirse que, sea en los centros universitarios, sea como medios personales de trabajo de los estudiantes, tienen un alto grado de uso las PC con aplicaciones de procesamiento de texto y base de datos. Se está incrementando progresivamente el acceso a Internet para la busca de información jurídica o de materias complementarias.

La incidencia de la globalización en los contenidos de la formación hay que buscarla sobre todo en las decisiones de cada universidad de incluir en sus plan de estudios materias determinadas en calidad de obligatorias de Universidad o de optativas.

Precisamente uno de los criterios básicos de la nueva ordenación de los planes de estudios es la de evitar su rigidez y posibilitar su ajuste a las necesidades de una sociedad en rápida transformación. En este sentido el informe técnico del grupo de trabajo que preparó el anteproyecto de directrices propias de título del Licenciado en Derecho indica: «[...] la carrera debe abrirse a los nuevos problemas y a las nuevas necesidades, creando disciplinas académicas de nueva planta o readaptando algunas de las tradicionales. Una de las razones que aconsejan que el nivel de troncalidad no sea muy alto es, precisamente, la necesidad de establecer planes de estudio flexibles, adaptables a las realidades cambiantes y abiertos a los nuevos métodos de enseñanzas y de aprendizaje. [...]. En definitiva, consideramos que ya no es posible definir lo que debe ser un jurista de manera unívoca y desde un plan de estudios 
rígido, en una sociedad como la actual, sometida a cambios acelerados». ${ }^{45}$

Como ejemplo se puede citar las siguientes materias optativas que aparecen en los planes de estudio de universidades españolas: Derecho internacional económico, Derecho del comercio internacional, Derecho del transporte internacional, Gestión del comercio exterior, nacionalidad, extranjería y ciudadanía europea, Derecho penal internacional y comunitario, Derecho procesal internacional, Derecho internacional público del mar.

3.1.12 Formación especialmente destinada a estudiantes extranjeros y relaciones de intercambio de estudiantes con facultades de Derecho extranjeras

La participación de la universidades españolas en la movilidad internacional de los estudiantes de Derecho presenta las siguientes manifestaciones más destacadas.

3.1.12.1 En la Universidad Complutense de Madrid, desde el curso académico 1996-97, se ha establecido un plan de estudios especial de Licenciado en Derecho (hispano-francés). El acceso al mismo está limitado por una elevada calificación de acceso a la Universidad y por la comprobación de un dominio suficiente del idioma francés.

La característica principal del plan es que una parte de las materias se cursan en la Facultad de Derecho de la Universidad Complutense y otras materias se cursan en una universidad francesa. Las materias citadas en segundo lugar son las siguientes: Derecho internacional público, Derecho comunitario, Derecho administrativo (partes del mismo), Derecho internacional económico, Derecho civil (partes del mismo), Derecho fiscal, Derecho internacional privado, Derecho mercantil (partes del mismo), grandes sistemas del Derecho, Hacienda pública francesa, Derecho del trabajo francés, Derecho constitucional (parte), Derecho de sociedades (parte), Derecho procesal civil francés. 
3.1.12.2 Movilidad de estudiantes en el ámbito europeo

Muchas universidades españolas, y dentro de ellas las facultades de Derecho, participan en el programa Sócrates-Erasmus de la Unión Europea para el intercambio de estudiantes, profesores y personal de administración entre las universidades de estos países y, además, Islandia, Liechtensein, Noruega, Polonia, República Checa, Hungría, Rumania y Chipre. Una de las acciones de ese programa es la de movilidad de estudiantes, que permite el intercambio de estudiantes entre las diferentes universidades europeas que han suscrito un acuerdo bilateral. Los estudiantes tienen garantizada la homologación de los estudios cursados en el extranjero mediante la aplicación del sistema ECTS.

Para facilitar que estudiantes europeos soliciten la estancia en una universidad española, algunas de estas universidades organizan e imparten en la universidad de procedencia cursos de breve duración de introducción al Derecho español (sistema de fuentes y terminología y conceptos jurídicos básicos). En la Universidad española los estudiantes suelen matricularse en créditos de libre configuración o de troncales de las llamadas «universales» (Derecho mercantil, comunitario, internacional público).

\subsubsection{Movilidad con Latinoamérica}

Principalmente afecta a estancias de profesores y de personal investigador. También a estudiantes de postgrado, pero no a estudiantes de licenciatura.

\subsubsection{Convenios bilaterales con universidades extranjeras}

Es muy frecuente que las universidades españolas concierten estos convenios, pero no es normal que den cobertura a intercambios de estudiantes de licenciatura.

3.1.13 Relaciones entre las universidades y las profesiones jurídicas. Influencia de estas profesiones en la orientación de la formación jurídica impartida por la Universidad

3.1.13.1 En la estructura institucional de la Universidad española el órgano de participación de la sociedad en la universidad es el Consejo Social. Según la Ley de Reforma Universitaria las competencias del Consejo Social son: la aprobación del presupuesto y de la programa- 
ción plurianual de la universidad, a propuesta del consejo de gobierno de la universidad, la supervisión de las actividades económicas de la Universidad y del rendimiento de sus servicios; también le corresponde promover la colaboración de la sociedad en la financiación de la universidad. Sus competencias no afectan, pues, directamente a aspectos académicos. La posibilidad de una incidencia indirecta es muy reducida.

Del Consejo Social puede formar parte, en calidad de vocal, alguna persona vinculada a los colegios profesionales, pero no necesariamente de profesiones jurídicas. No es una vía significativa de influencia de las profesiones jurídicas en la formación que se imparte en las facultades de Derecho.

3.1.13.2 El anteproyecto de directrices propias para los planes de estudio conducentes al del título de Licenciado en Derecho fue sometido a información pública, con remisión de los trabajos, entre otros, a las organizaciones colegiales profesionales, con posibilidad de formular propuestas alternativas totales o parciales o, de modo más genérico, observaciones, sugerencias y comentarios.

Emitieron informe, con la clase de contenido que se ha indicado en último lugar, el Consejo General de la Abogacía Española, el Consejo Nacional del Notariado y el Colegio Nacional de Registradores de la Propiedad y Mercantiles de España y algunos colegios de profesiones jurídicas de ámbito territorial.

\subsubsection{Relación mediante convenios de colaboración}

Es la vía de relación más importante.

Los objetivos más frecuentes de estos convenios son facilitar por el colegio profesional o la institución correspondiente de las prácticas formativas de los estudiantes ("Practicum») y la organización de cursos de formación para profesionales o de cursos universitarios de postgrado.

3.1.14 Profesorado universitario de Derecho y dedicación profesional a la práctica del Derecho.

Es conveniente distinguir dos clases de profesores de Derecho -prescindiendo ahora del personal docente e investigador en formación-: profesores profesionales -que en las universidades públicas tienen la condición de funcionarios- y profesionales de las diferentes profesiones 
jurídicas que de modo accesorio tienen alguna dedicación a la docencia.

3.1.14.1 La primera clase de profesores (profesores profesionales con calidad de funcionarios) no puede dedicarse a la práctica del Derecho desde puestos de trabajo del sector público (por ejemplo: juez, miembro del Ministerio Público), porque la legislación administrativa general establece una rígida incompatibilidad. Pueden dedicarse a la práctica del Derecho en el sector privado, acogiéndose a un régimen especial de dedicación funcionarial que implica una importante reducción de las retribuciones.

En una universidad significativa -por su tamaño, por su importancia y por su entorno socioeconómico- como la Universidad de Valencia, el porcentaje de profesores funcionarios de la Facultad de Derecho con dedicación a tiempo parcial es del 10 por ciento en el año 1997. A mi juicio, la motivación principal de la dedicación a la abogacía ha sido y es de naturaleza económica. Una adecuada retribución del profesorado universitario e ingresos complementarios por publicaciones y participación en actividades de formación parecen haber influido en unos porcentajes bajos de dedicación a tiempo parcial.

Por otra parte, los profesores a tiempo completo pueden adquirir experiencia en la práctica jurídica mediante la emisión de dictámenes e informes técnicos -actividad facilitada por su legislación funcionarial especial-y mediante el desempeño de funciones de magistrado suplente en los tribunales (véase apartado I.1 de este informe).

3.1.14.2 La participación en la docencia de las facultades de Derecho de los profesionales de las diversas profesiones jurídicas la instrumenta la legislación universitaria a través de la figura del profesor asociado, con una dedicación máxima de seis horas semanales a la docencia.

Los profesores asociados de las facultades de Derecho suelen proceder de los profesionales del Derecho que son empleados públicos (jueces, miembros del Ministerio Público, secretarios judiciales, funcionarios administrativos) y, en menor medida, de la abogacía.

Según la universidad, los profesores asociados en las facultades de Derecho pueden llegar a suponer entre un 20 y un 30 por ciento de sus profesores. 


\subsection{Formación profesional}

La situación española presenta, en este aspecto, peculiaridades importantes.

La razón principal es que, en España, el acceso a la condición de abogado no requiere, después de tener el título de Licenciado en Derecho, ninguna formación profesional específica, aunque esta situación está en proceso indefinido de cambio y ya están vigentes algunas exigencias limitadas de formación profesional. Expondré la situación actual y su tendencia de evolución en un apartado sobre la formación profesional de los abogados.

Por otra parte, para el acceso a la condición de juez es tan importante el procedimiento de selección inicial como el periodo de formación en un centro específico. Dedicaré un apartado a la selección y formación profesional de los jueces.

En un apartado final expondré muy brevemente la formación profesional de otras profesiones jurídicas.

3.2.1 Selección y formación profesional (inicial y continuada) de los jueces en España

\subsubsection{Selección previa al acceso a la Escuela Judicial}

Se realiza, principalmente, mediante oposición libre entre licenciados en Derecho, para lo que se ofrece un número limitado de plazas. La oposición consiste en tres exámenes sucesivos y eliminatorios en los que se comprueba la amplitud y corrección de los conocimientos sobre las diversas materias jurídicas de acuerdo con un temario previamente publicado. Las comisiones evaluadoras están formadas por magistrados, profesores de universidad, abogados, miembros del Ministerio Público y del cuerpo funcionarial de abogados del Estado.

Una de cada cuatro plazas convocadas lo son según un procedimiento selectivo mixto de concurso de méritos y oposición entre licenciados en Derecho con seis años de ejercicio en otra profesión jurídica o en la docencia del Derecho. Esta es una de las vías previstas por la Ley Orgánica del Poder Judicial para facilitar la comunicación entre las profesiones jurídicas. La valoración de la misma no es positiva. Concretamente, el Consejo General del Poder Judicial ha afirmado: «si bien es cierto que se produce una elevada participación cuantitativa, da la 
impresión de concebirse esta forma de acceso como un simple medio de evitar la preparación teórica exigida en la oposición». ${ }^{46}$

3.2.1.2 Formación profesional inicial: estudios en la Escuela Judicial y periodo de Juez en prácticas

Los aspirantes a la carrera judicial que resultan seleccionados han de realizar un curso teórico-práctico de un año de duración en la Escuela Judicial dependiente del Consejo General del Poder Judicial ${ }^{47}$.

Las materias incluidas en el curso son las siguientes: $1^{\circ}$ ) materias jurídicas: Derecho civil, penal, procesal civil, procesal penal, constitucional y orgánico judicial, más algunas materias especiales; $2^{\circ}$ ) materias complementarias: medicina legal, economía y contabilidad; $3^{\circ}$ ) materias instrumentales: informática, técnicas de comunicación y argumentación, psicología jurídica.

Los métodos docentes principalmente aplicados son los siguientes: método del caso, contestación a cuestionarios sobre temas específicos, dictámenes o informes, estancias y visitas a juzgados, examen y análisis de asuntos y expedientes, simulaciones de actuaciones procesales, debates, redacción de documentos y de resoluciones.

Las evaluaciones se realizan por el consejo de profesores de la Escuela, a partir de una detallada evaluación continuada de las actividades y trabajos realizados.

Después de las tres primeras evaluaciones, los alumnos considerados aptos han de realizar un año de prácticas jurisdiccionales, preferentemente en calidad de jueces adjuntos -con funciones de auxilio y colaboración al juez titular del juzgado-, y, si lo anterior no fuera posible, como jueces sustitutos o de refuerzo (con plenitud de funciones en un juzgado cuyo titular es otro juez).

Tras esta etapa de formación práctica se realiza la cuarta evaluación, cuya superación determina el acceso definitivo a la condición de juez. No hay, pues, examen de salida, pero el sistema de evaluación de la

46 Consejo General del Poder Judicial, Memoria que el Consejo general del Poder judicial eleva a las Cortes Generales, Madrid, 1997, p. 75.

47 La información sobre ese curso y el período de prácticas posterior que presento en el texto es un resumen del Dossier docente del curso 1998-1999, Centro de Formación inicial, Escuela Judicial. Agradezco la colaboración de la Prof. Dra. Teresa Armenta Deu, Catedrática de Derecho Procesal y profesora ordinaria de la Escuela Judicial. 
etapa de formación profesional posterior a la selección inicial es riguroso y puede determinar la exclusión de algún aspirante.

\subsubsection{Formación continuada de jueces y magistrados}

El Consejo General del Poder Judicial ha desarrollado y perfeccionado desde tiempo un amplio plan de formación continuada.

La estructura del mismo consiste en un plan estatal de formación y en un plan descentralizado de formación.

El plan estatal de formación se desarrolla en Madrid, en la sede del servicio de formación continuada de la Escuela Judicial. Consiste en cursos y seminarios de corta duración, de carácter monográfico, destinados a grupos de unos cuarenta jueces y magistrados. El profesorado se extrae de las diversas profesiones jurídicas, incluidos los docentes universitarios. Los contenidos de los cursos y seminarios son seleccionados rigurosamente con participación de los destinatarios y sus resultados son recogidos en publicaciones monográficas que se remiten a todas las bibliotecas de los juzgados y tribunales.

El plan estatal comprende también actividades de estudio y debate sobre reformas legislativas de gran importancia y la colaboración del Consejo General del Poder Judicial en actividades de formación organizadas por otras profesiones jurídicas y por la Universidad, a las que tienen acceso especial los jueces y magistrados.

El plan descentralizado de formación es coordinado por el Consejo General del Poder Judicial y su finalidad es aproximar las actividades formativas a todos los puntos del Estado.

La formación continuada de jueces y magistrados es, en principio, voluntaria. El Consejo General del Poder Judicial fomenta la participación en la misma, mediante compensación económica de desplazamientos y estancias y facilitando la sustitución temporal en los puesto de trabajo.

Una formación complementaria obligatoria, posterior a la inicial de la Escuela Judicial, la prevé la ley para los magistrados no especialistas que pretendan acceder a plazas de órganos jurisdiccionales con competencia en Derecho del Trabajo y de la Seguridad Social y en Derecho Administrativo.

El Consejo General del Poder Judicial se ha manifestado partidario de extender la obligatoriedad de una formación posterior a la inicial a supuestos distintos a los ya previstos por la ley de provisión de puestos jurisdiccionales en órganos con competencias especializadas-menores, 
familia, vigilancia penitenciaria-, de establecer actividades de formación obligatoria en casos de reformas legales con importante incidencia en la jurisdicción y de priorizar la participación en la formación continuada de los jueces de nuevo ingreso.

3.2.2 Formación profesional de los abogados en España. Referencia a otras profesiones jurídicas liberales

En líneas generales puede decirse que el acceso a la condición de abogado no requiere en España ninguna formación profesional inicial y que la participación de los abogados en actividades de formación continuada es esporádica. Esta apreciación puede extenderse a los procuradores de los tribunales y a los graduados sociales, por lo que la exposición más detallada, que se realiza a continuación respecto a la situación de los abogados, ilustra de modo suficiente también sobre la situación de las otras profesiones jurídicas liberales.

3.2.2.1 Situación de Derecho respecto de la formación profesional inicial de los abogados

En esta apartado exponemos la situación sobre la formación profesional de los abogados de acuerdo con lo que prescriben las normas vigentes en España. Hay que distinguir tres supuestos. El primero constituye la regla general. Los dos segundos son supuestos especiales de diferentes características en los que está empezando a ser exigida una cierta formación profesional o un acreditamiento específico de las aptitudes profesionales.

a) Regla general: carácter no preceptivo de la formación profesional inicial.

Para acceder a la profesión de abogado se requiere la incorporación al correspondiente colegio profesional y los requisitos necesarios para esta incorporación son: ser español, mayor de edad, Licenciado en Derecho, no tener antecedentes penales que inhabiliten para el ejercicio profesional, cumplir las obligaciones económicas colegiales y de mutualidad de previsión profesional y cumplir las obligaciones tributarias. Expresamente dispone la disposición reguladora de la abogacía que los colegios no podrán negar la incorporación a quienes cumplan los anteriores requisitos. No es necesaria, pues, normativamente, ninguna formación profesional específica. 
De hecho, sin embargo, el adiestramiento profesional es necesario y se lleva a cabo de dos modos. El modo tradicional era el aprendizaje en despachos de abogados ya consolidados, en los que el abogado principiante realiza una actividad mixta de aprendizaje práctico y colaboración; este modo de formación entró en crisis con el aumento del número de licenciados (y también por la diversificación de su extracción social). Un modo más actual de satisfacer la necesidad de formación profesional son las escuelas de práctica jurídica, a las que nos referiremos con mayor detalle en el siguiente apartado B.

b) Regla especial: profesionales nacionales de un estado miembro de la Unión Europea y otros Estados partes en el Acuerdo sobre el Espacio Económico Europeo, con título obtenido en alguno de dichos Estados, que deseen ejercer en España la profesión de abogado.

De acuerdo con las disposiciones vigentes en España para transponer la Directiva 89/48/CEE del Consejo de las Comunidades Europeas de 21 de diciembre de 1988, para que el interesado pueda ingresar en un colegio de abogados habrá de solicitar y obtener del Ministerio de Justicia el reconocimiento de su título.

La resolución del Ministerio de Justicia puede ser de reconocimiento, pero con exigencia de que el interesado supere pruebas de aptitud sobre contenidos generales del ordenamiento jurídico español, ante una comisión de valuación designada por el Ministerio de Justicia, compuesta por dos funcionarios, dos profesores universitarios y dos abogados. También puede resolver el reconocimiento sin esa exigencia, si el interesado acredita una experiencia profesional o una formación en España que demuestren un conocimiento suficiente del Derecho español.

c) Regla especial: acceso a prestar servicios como abogado en el régimen de asistencia jurídica gratuita.

Los colegios de abogados gestionan los servicios de asistencia y defensa mediante abogado, uno de los componentes del derecho a asistencia jurídica gratuita de las personas con insuficiencia de recursos económicos. La prestación de esos servicios está financiada con fondos públicos que reciben los colegios, con destino a retribuir a los profesionales encargados del asunto.

La nueva regulación en España de la asistencia jurídica gratuita ha sido la oportunidad para introducir, con alguna amplitud, la exigencia de cierta formación profesional específica para los abogados principiantes. 
Según disposiciones de esa nueva regulación, el Ministerio de Justicia, previo informe de los Consejos Generales de la Abogacía y de los Colegios de Procuradores de los Tribunales de España, establecerá los requisitos generales mínimos de formación y especialización necesarios para prestar los servicios de asistencia jurídica gratuita, con objeto de asegurar un nivel de calidad y de competencia profesional que garantice el derecho constitucional a la defensa. Dichos requisitos serán de obligado cumplimiento para todos los colegios profesionales y podrán ser complementados por las regiones autónomas con competencia en esta materia. Salvo error por mi parte, la disposición reguladora de tales requisitos aun no ha sido dictada, pero los colegios exigen para el acceso a la relación de abogados que pueden recibir encargos de asuntos de asistencia jurídica gratuita, el acreditamiento de una cierta formación profesional, principalmente en las escuelas de práctica jurídica.

3.2.2.2 Centros específicos para la formación profesional de los abogados: las escuelas de práctica jurídica. La formación contínua de los abogados.

De hecho, ya que no de Derecho, las escuelas de práctica jurídica son los centros específicos en los que se realiza la formación profesional de los abogados. La organización y funcionamiento de estos centros es muy diversificada. Sintetizo, a continuación, una información general relevante para los puntos del apartado 3.2, 2 del cuestionario. ${ }^{48}$

a) Las escuelas están relacionadas organizativamente bien sea sólo con un colegio de abogados o dependen de una estructura de colaboración entre la Universidad, en concreto su Facultad de Derecho, y el Colegio de Abogados.

b) De la docencia se encargan abogados en ejercicio, otros profesionales, funcionarios de la Administración de Justicia y de la Administración pública y profesores de la universidad.

c) En cuanto al contenido de la docencia, las escuelas suelen ofrecer, por una parte, un llamado curso general -que tiene por fin un adiestra-

48 Sobre el tema pueden consultarse las aportaciones sobre la formación profesional del abogado, publicadas en El abogado, formación, deontologia y organización del despacho profesional, (Gutiérrez Alviz y Conradi, Ed.), Pamplona, 1994, pp. 41-68. He dispuesto también de la información sobre el curso general de la Escuela de Práctica Jurídica de Murcia y de las informaciones en las web de los Colegios de Abogados de Madrid y de Barcelona. 
miento general para el ejercicio de la abogacía y que describiré después, $y$, por otra, diversos cursos especiales. A título de ejemplo, estos son algunos de los cursos especiales: Comercio exterior y legislación internacional, Derecho inmobiliario, Derecho matrimonial, Derecho de sociedades, Contabilidad y análisis financiero, técnicas de negociación y mediación, Técnicas de expresión oral, Arrendamientos urbanos, Derecho hipotecario, Derecho urbanístico, Derecho marítimo, Derecho de la construcción, Utilidad y uso de Internet, Derecho del mercado de valores.

d) El llamado curso general, que se imparte en algunas escuelas de práctica jurídica, tiene una duración variable, que puede llegar hasta los dos años y alcanzar una docencia de 800 horas.

El número de plazas está limitado, pero el acceso al curso no depende de exámenes previos, sino de la prelación temporal de las solicitudes.

Los contenidos y los métodos docentes son de dos clases.

Por un lado se imparte formación en técnicas de actuación profesional, entendidas como modos de aplicación de los conocimientos teóricos adquiridos respecto a las diversas partes del ordenamiento, tanto en su realización judicial como extrajudicial. Además se incluye formación teórico-práctica en Deontología profesional, Informática aplicada al Derecho, Oratoria y escritura forenses y Psicología forense. Los grupos de estudiantes no han de exceder de treinta.

Por otro lado, se persigue un adiestramiento para el ejercicio profesional ante juzgados y tribunales y ante oficinas públicas, mediante la asistencia a actuaciones judiciales -previa preparación y con análisis posterior- o con la simple visita para conocer la organización y funcionamiento. Además, son examinados y comentados audiovisuales de contenido jurídico y se realizan prácticas en aplicaciones informáticas de utilidad.

Otras actividades son la realización de trabajos jurídicos prácticos bajo la supervisión de un tutor de la Escuela y, si es posible, la participación en asuntos de asistencia jurídica gratuita, como auxiliares del abogado encargado.

e) La formación continuada de los abogados puede realizarse a través de los cursos especiales que ofrecen las escuelas de práctica jurídica y de los múltiples cursos de especialización y perfeccionamiento que ofrecen las universidades y otras instituciones. Cosa distinta es la fre- 
cuencia con la que abogados ya consolidados en la profesión demandan esa formación, que probablemente es baja. Algunos grandes despachos de abogados planifican actividades internas de formación.

3.2.3 Breve referencia a la selección y formación profesional (inicial y continuada) de profesiones jurídicas que suponen una relación de empleo público o el ejercicio privado de algunas funciones públicas

\subsubsection{Secretarios judiciales y miembros del Ministerio Fiscal}

$\mathrm{El}$ acceso a estas profesiones jurídicas requiere un examen inicial y un periodo de formación en el Centro de Estudios Jurídicos de la Administración de Justicia, dependiente del Ministerio de Justicia. ${ }^{49}$

El primero se convoca para cubrir un número limitado de plazas, y se realiza según un temario previamente conocido, que comprende diversas materias jurídicas estudiadas en la licenciatura, lo que permite evaluar, principalmente, el grado de conocimientos retenidos sobre esas materias.

El período de formación en el Centro de Estudios Jurídicos de la Administración de Justicia de los aspirantes al Ministerio Fiscal es de seis meses. Su contenido consiste en cursos teórico-prácticos generales sobre la estructura del Ministerio Fiscal y sus funciones ante cada jurisdicción, en cursos especiales sobre materias complementarias de las jurídicas o de profundización en algunas materias jurídicas, y en la realización de prácticas en las fiscalías bajo la tutela de miembros del Ministerio Fiscal.

Los aspirantes a secretario judicial han de permanecer en el Centro de Estudios Jurídicos aproximadamente seis meses. El contenido de la formación son cursos teórico-prácticos sobre Derecho procesal civil y penal, sobre algunos temas de especial importancia profesional (costas judiciales, ejecución forzosa, organización de la secretaría judicial) y en la realización de prácticas tuteladas en secretarías de juzgados y tribunales.

49 Agradezco la colaboración del Prof. Dr. José Manuel Chozas, Profesor titular de Derecho Procesal y Jefe de Estudios del Centro de Estudios Jurídicos de la Administración de Justicia, que me ha remitido información sobre la formación inicial y continuada, que realiza o coordina el Centro. 
Para ambas profesiones jurídicas existen planes de formación continuada, consistentes en cursos y seminarios sobre temas en cuya determinación influyen, de modo importante, los propios destinatarios de la formación, para garantizar el ajuste a las necesidades profesionales. Unas actividades se realizan de modo centralizado, otras de modo descentralizado en todo el territorio del Estado para facilitar la participación. Para esta formación se pretenden establecer relaciones de colaboración entre las distintas funciones públicas que actúan en la administración de justicia (jueces, secretarios y fiscales).

3.2.3.2 Notarios, registradores de la propiedad y mercantiles, corredores de comercio

El acceso a la profesión se realiza mediante examen selectivo, convocado para cubrir un número limitado de plazas. Consta de un número y calidad de pruebas diferentes para cada profesión y se realiza según temario previo que comprende diversas materias jurídicas -de modo principal jurídico-privadas- $y$, en el caso de los corredores de comercio, materias de economía y contabilidad.

La evaluación se realiza por comisiones nombradas oficialmente $y$, atendida la diversidad de pruebas que componen el procedimiento selectivo, permite verificar tanto el nivel de conocimientos teóricos de los aspirantes, cuanto sus aptitudes para aplicar esos conocimientos en las especificas funciones encomendadas a la profesión.

No están establecidos periodos de formación profesional inicial en centros oficiales. Las actividades de formación continuada son organizadas por los correspondientes colegios profesionales, con diferentes grados de planificación.

3.2.4 y 3.2.5. Debates abiertos sobre la formación de los juristas y reformas normativas sobre el tema

\section{A) Formación en la Universidad}

Para los temas que son objeto relevante de discusión respecto a este ámbito de la formación de los juristas lo más ilustrativo es remitirse a las conclusiones de la Reunión de los Decanos de la Facultades de Derecho de España, celebrado en Granada, en junio de 1997, que resumidamente son las siguientes: 
1) Es conveniente que las directrices de los planes de estudio permitan aumentar la docencia en las materias jurídicas obligatorias en todas la universidades, por que esto favorecerá el refuerzo del aspecto generalista y formativo de los estudios de la licenciatura. Algún avance normativo en este sentido es considerado insuficiente.

2) Es conveniente que la duración prevista de los estudios se amplíe de cuatro a cinco años.

3) La introducción de materias optativas ha de ser progresiva, pero ha de tener mayor proporción en el segundo ciclo de la licenciatura.

4) La importancia de la docencia práctica y del llamado "Practicum» debe ser acompañada de un aumento en la financiación que posibilite una mejor implantación de esos métodos docentes.

En cuanto a las reformas normativas, está abierto un proceso de reforma de las directrices a las que deben sujetarse los planes de estudio -no sólo de Derecho- cuyos principales objetivos son: evitar la atomización de las materias objeto de docencia, porque dificulta la organización del trabajo individual de los estudiantes y la planificación de los servicios docentes, y permitir que las universidades puedan incrementar el porcentaje de docencia de las materias obligatorias generales en cada plan de estudios.

B) Selección y formación profesional de los jueces

Como cuestiones objetivamente importantes en este campo apunto las planteadas por el Consejo General del Poder Judicial en el Libro Blanco de la Justicia.

1) Es conveniente que los planes de estudio de la facultades de Derecho prevean una especialización orientada a la función jurisdiccional..$^{50}$ Esto posibilitaría una opción más consciente de quienes participan en la selección inicial para el acceso a la carrera judicial.

2) Es necesario introducir en la selección inicial técnicas que permitan reducir el número de aspirantes después de una primera prueba, para que pueda actuar una comisión evaluadora única, que evite la dispersión de criterios de evaluación. ${ }^{51}$ 
3) Es conveniente unificar los procedimientos de selección inicial para el ingreso en la carrera judicial y en la carrera fiscal, que deberían realizarse según un temario único y ante una misma comisión evaluadora. ${ }^{52}$

4) El procedimiento de ingreso en la carrera judicial especialmente previsto para otros profesionales jurídicos, debería requerir más años de dedicación previa a la correspondiente profesión jurídica, y, en la categoría de magistrado, convocarse para puestos de la especialización del profesional y requerir un periodo de prácticas en tribunales. ${ }^{53}$

5) La formación profesional inicial en la Escuela Judicial ha de favorecer la preparación para una correcta motivación de las resoluciones judiciales, la capacitación para utilizar técnicas instrumentales no jurídicas. El periodo de prácticas jurisdiccionales ha de ser seguido de otro periodo, en la Escuela, de reflexión crítica sobre la experiencia práctica, para evitar la adquisición de rutinas de actividad por parte de los nuevos jueces. ${ }^{54}$

6) La formación continuada ha de ser incentivada, vinculando de modo importante a la participación en la misma la promoción profesional o la facilitación de ésta. En algunos supuestos la formación continuada habría de ser obligatoria: primeros años de ejercicio de los jueces, reformas legislativas importantes.

C) Formación profesional de los abogados

Es, sin duda, el área en la que hay más y más importantes cuestiones abiertas. Pero no existe un debate sistemático entre las instituciones con capacidad para pronunciarse sobre el asunto. Sólo se han manifestado algunas opiniones relevantes. Intentaré resumir el estado de la cuestión.

En primer término, existe unanimidad en la necesidad de establecer una formación profesional obligatoria para el acceso a la profesión de abogado. Como expresiones destacadas de esta opinión apuntaré, de

54 Consejo General del Poder Judicial, Libro Blanco de la Justicia, Madrid, 1997, pp. 50-51. 
un lado, que en el V Congreso de la Abogacía Española, celebrado en Palma de Mallorca, en abril de 1989, se aprobó por amplia mayoría la conclusión de que «la formación teórico-práctica de un Licenciado en Derecho para el ejercicio de la abogacía ha de ser obligatorian; ${ }^{55}$ por otro, el Consejo General del Poder Judicial sostiene la conveniencia «de establecer algún procedimiento de formación obligatoria previo al inicio del ejercicio profesional". ${ }^{56}$

Sobre las características del modelo de formación profesional a implantar no existe suficiente definición.

En las conclusiones del V Congreso de la Abogacía Española se proponían tres medios alternativos: formación bajo la dirección de un abogado experimentado con adscripción a una Escuela de Práctica a efectos de control y evaluación; curso en una Escuela de Práctica para la abogacía con posterior prueba de aptitud; prueba de aptitud directa para acreditar los conocimientos técnico-prácticos suficientes prescindiendo de los dos primeros medios de formación. ${ }^{57}$

El Consejo General del Poder Judicial indica que el procedimiento de formación obligatoria "debería venir condicionado a la superación de algún tipo de prueba oficial e inspirarse en cualquiera de los sistemas de acceso a la profesión implantados en los diferentes países de la Unión Europea». ${ }^{58}$

En relación con la formación profesional del abogado, no como sustitutivo del sistema que pueda establecerse, sino como elemento complementario del mismo, tanto el Consejo General del Poder Judicial, ${ }^{59}$ como el Consejo General de la Abogacía Española, ${ }^{60}$ se refieren a la responsabilidad de las universidades, que han de asumir mediante la exigencia de elevados niveles de formación y estableciendo posibilidades de preespecialización en práctica forense, con la colaboración de los colegios de abogados.

$55 V$ Congreso de la Abogacía Española. Conclusiones, Madrid, 1989, p. 37.

56 Consejo General del Poder Judicial, Libro Blanco de la Justicia, Madrid, 1997, p. 38.

$57 V$ Congreso de la Abogacia Española. Conclusiones, Madrid, 1989, p. 37.

58 Consejo General del Poder Judicial, Libro Blanco de la Justicia, Madrid, 1997, p. 38.

59 Consejo General del Poder Judicial, Libro Blanco de la Justicia, Madrid, 1997, p. 38.

60 Informe del Consejo General de la Abogacía Española respecto de directrices generales de los planes de estudios conducentes al titulo de Licenciado en Derecho, en Consejo de Universidades, Reforma de las enseñanzas universitarias. Titulo: Licenciado en Derecho, Madrid, 1988, pp. 630-631. 
A pesar de lo anterior y de diversas opiniones expresadas en favor de alguna participación de la universidad en la formación práctica de los abogados, al establecerse la primera exigencia legal de formación profesional para el abogado -la requerida para prestar servicios de asistencia jurídica gratuita-, no se ha dispuesto que la institución universitaria sea oída para concretar los requisitos de esa formación, sino que la audiencia se ha limitado a las organizaciones colegiales de abogados y procuradores.

Por otra parte, en la Reunión de Decanos de la Facultades de Derecho de las Universidades de España, celebrada en Granada en junio de 1997, se adoptó el acuerdo de que !sólo las enseñanzas de tipo práctico tuteladas y dirigidas por las facultades de Derecho podrán ser tomadas como requisitos necesarios para el ejercicio de la profesión de abogado o de cualesquiera otras profesiones jurídicas». Estas enseñanzas pueden organizarse perfectamente a través de escuelas de práctica jurídica en las que las facultades de Derecho deberán contar inexcusablemente con la colaboración, muy primordial, de los colegios de abogados, sin perjuicio de la participación de otros colegios profesionales e instituciones públicas o privadas relacionadas con las restantes profesiones jurídicas.

En consecuencia, parece evidenciarse una importante divergencia sobre el grado de responsabilidad que correspondería a la institución universitaria y a las organizaciones colegiales en esa formación profesional.

3.2.6. Influencia de la competencia internacional sobre la situación de las profesiones jurídicas

La competencia internacional suscita preocupación en la abogacía española. Lo revelan objetivamente dos conclusiones aprobadas en el Tema VI del V Congreso de la Abogacía Española. Según la primera de ellas se debe «regular urgentemente, a través de los organismos rectores de la abogacía, las normas necesarias para el establecimiento de mercados extranjeros en nuestro país que, por ausencia de regulación legal, escapan a los controles deontológicos y no cumplen las normas de publicidad impuestas a los abogados españoles, sean o no comunitarios». ${ }^{61} \mathrm{Y}$ en otra conclusión sobre el mismo tema, se acuerda «solicitar

$61 V$ Congreso de la Abogacía Española. Conclusiones, Madrid, 1989, p. 42. 
de los organismos rectores de la abogacía la creación de comisiones que sean necesarias para el estudio, tanto del ejercicio profesional a través de despachos multiprofesionales como a través de despachos multinacionales, con especial en cuanto a unos y a otros, tanto a las cuestiones de independencia como de deontología y secreto profesional».

Sin embargo, este factor no parece haber influido en el sentido de provocar una crisis significativa en el modo de prestarse los servicios de asistencia jurídica en el ámbito español, crisis que determinara incluso el cierre de despachos.

La oferta de estos servicios sigue creciendo, como también crece la demanda de los mismos. ${ }^{62}$ La estructura organizativa preponderante sigue siendo la de los despachos individuales -estrictamente o con abogados ayudantes- o de muy pequeño tamańo, aunque también son cada vez más frecuentes las formas de asociación y agrupamiento de abogados, pero sin llegar a las grandes empresas de servicios de asistencia jurídica que existen en algunos países. ${ }^{63}$

Entre las razones de estas formas de asociación o de agrupamiento está la internacionalización, pero hay también otras. Según De Angulo están entre tales razones "el propósito de mejorar la oferta de servicios al cliente en un mundo especializado, masificado e internacionalizado; de reducir los crecientes costes de funcionamiento compartiéndolos entre diferentes profesionales, cuando han resultado encarecidos por las actuales exigencias de prestación del servicio profesional e incluso por las nuevas tecnologías instrumentales (la informática, pero también la telemática y la burótica en general); o de incidir así en un mayor segmento de clientela en un mercado altamente competitivo". ${ }^{64}$

62 S. Pastor Prieto, $;$ Ah de la justicia! Politica judicial y economia, Madrid, 1993, p. 275.

63 S. Pastor Prieto, ;Ah de la justicia! Política judicial y economía, Madrid, 1993, p. $275-$ 277; L. De Angulo Rodríguez, El ejercicio de la abogacía en el año 2000, en El abogado, formación, deontologia y organización del despacho profesional, (Gutiérrez Alviz y Conradi, Ed.), Pamplona, 1994, pp. 29-32, V. Cortés Domínguez, Organización del despacho profesional del abogado, en la obra colectiva acabada de citar, pp. 115-124; J.L. Vásquez Sotelo, Organización del despacho profesional del abogado, en la obra colectiva acabada de citar, pp. 135-140.

64 L. De Angulo Rodríguez, "El ejercicio de la abogacía en el año 2000", en El abogado, formación, deontologia y organización del despacho profesional, (Gutiérrez Alviz y Conradi, Ed.), Pamplona, 1994, p. 31. 


\section{Conclusiones}

1. Relaciones entre la evolución de la litigiosidad civil y la evolución de las profesiones jurídicas

2. En términos generales mi apreciación es que a lo largo del siglo $\mathrm{XX}$, de un contacto con el tráfico jurídico, y con la litigiosidad que deriva del mismo, de carácter preponderantemente individual, en el que, además, los interesados procedian de grupos sociales reducidos (clases altas y una clase media no amplia), y que, en cuanto a la frecuencia, era un contacto esporádico y ocasional, se ha evolucionado hacia una generalización de la demanda de servicios jurídicos y hacia una diversificación de esa demanda.

Por un lado, se ha ampliado el número de personas que participan con frecuencia en el tráfico jurídico, pueden, por lo tanto, encontrarse en situaciones de litigiosidad y se convierten en demandantes de servicios jurídicos. Ese crecimiento cuantitativo se debe, principalmente, al aumento del nivel económico de la población, que da lugar a un incremento de las transacciones. Pero también es importante el aumento del nivel cultural, que determina que, incluso cuando faltan recursos económicos para el modo ordinario de acceso a los servicios jurídicos, se hayan desarrollado formas nuevas de acceso a los mismos o se hayan reformado sustancialmente algunas formas tradicionales (por ejemplo, la asistencia jurídica gratuita con financiación pública).

La generalización de la demanda de servicios jurídicos conduce, inexorablemente, a una diversificación de los servicios que se demandan.

Es sin duda importante la incidencia que en el modo de ejercerse las profesiones jurídicas tiene el gran volumen de participación en el tráfico jurídico y en la litigiosidad vinculada al mismo, de los agentes económicos que se mueven en el ámbito de la mundialización, pero el tipo de servicios jurídicos que estos agentes necesitan es obviamente distinto de los que demandan otros sujetos jurídicos, que participan de modo significativo en la vida jurídica en ámbitos territorialmente más tradicionales, pero con una intensidad históricamente desconocida.

La diversificación de la demanda de servicios jurídicos está ligada a diferentes situaciones de los sujetos jurídicos: tamaño de las empresas, proyección internacional o no de las mismas en cuanto a su control social o en cuanto a su área de actividad, personas o entidades que se 
hallan con más frecuencia ante problemas jurídicos de carácter común a todos ellos (consumidores, trabajadores, grupos de empresas pertenecientes a sectores con problemas comunes), personas con problemas jurídicos de carácter individual y esporádico.

\section{A) Influencia en la profesión de abogado}

Las circunstancias reseñadas han incidido de manera muy directa y ágil en el modo de ser ejercida la profesión de abogado. De la forma tradicionalmente predominante del despacho individual, en el que podían trabajar más abogados pero subordinados al abogado titular, se ha evolucionado a una multiforme prestación de servicios ${ }^{65}$

De esa diversidad de formas de prestación de los servicios de asistencia jurídica se pueden destacar las siguientes:

a) Abogados integrados en la propia organización de las empresas.

b) Abogados especializados en diferentes materias jurídicas, que dan respuesta a las necesidades derivadas de la creciente complejidad y movilidad de la ordenación jurídica.

c) Despachos interprofesionales, que reúnen la prestación de servicios de asistencia jurídica y servicios profesionales de carácter económico, contable, de arquitectura, de ingeniería..., que demandan de manera conjunta determinadas clases de clientes.

d) Diversas clases de colaboración estable y de agrupamiento de abogados con el fin de combinar la satisfacción de la necesidad de especialización con la de dar un tratamiento completo a los casos, cualesquiera sean los aspectos jurídicos que presenten.

e) Despachos individuales o de pequeño tamaño de abogados generalistas o expertos en el tráfico jurídico y en la litigiosidad de ámbitos territorialmente localizados.

f) Servicios jurídicos en asociaciones de diversa índole (sindicatos, asociaciones empresariales, consumidores, ecologistas) a los que se facilita el acceso de los miembros de la asociación o de personas interesadas en los fines de la misma.

65 Pueden consultarse con utilidad los trabajos de De Angulo, Cortés Domínguez y Vázquez Sotelo en El abogado, formación, deontología y organización del despacho profesional, (Gutiérrez Alviz y Conradi, Ed.), Pamplona, 1994. 
g) Aseguramiento de la prestación de servicios jurídicos, como garantía complementaria del aseguramiento frente a determinados riesgos (responsabilidad civil por circulación de automóviles, por riesgos del hogar).

h) Superación de la prestación de asistencia jurídica gratuita como un deber ético y organización de la misma como una prestación estatal equilibradora de desigualdades sociales.

B) Influencia en la profesión de juez o en el modo de prestación de la función judicial

La incidencia en el perfil profesional del juez y en el modo de organizarse la prestación de la función jurisdiccional tiene un ritmo más lento, porque no hay capacidad de autoajuste a las nuevas necesidades, sino que la adecuación depende del régimen normativo de la jurisdicción.

La abundancia y la diversidad cualitativa de los conflictos jurídicos que han de ser resueltos por los jueces, ha hecho notar su influencia en las necesidades de formación de los mismos y en la regulación del modo en el que han de desempeñar su función y aun debe tener más peso en futuras reformas sobre estas materias.

Compartiendo algunas conclusiones de un reflexivo análisis sobre el contexto español, ${ }^{66}$ entiendo que las principales repercusiones producidas y que deberán seguir produciéndose en el ejercicio de la función jurisdiccional son las siguientes:

a) Necesidad de una formación especializada de los jueces y de una especialización de los órganos que son competentes para decidir las cuestiones litigiosas, porque, en defecto de esa especialización, la diversidad y complejidad de las normas jurídicas -que no son características arbitrariamente buscadas, sino resultado de la complejidad de la vida social a la que aquéllas están destinadas- pueden ser completamente desconocidas en el momento de su aplicación judicial.

b) Necesidad de crear los instrumentos adecuados para que los contenidos técnicos cada vez más complejos y más frecuentes en las nor-

66 Me refiero al ensayo de V. Hernández Martín, Independencia del juez y desorganización judicial, Madrid, 1991, especialmente pp. 157-190. 
mas jurídicas y en los litigios que se suscitan ante los jueces, puedan ser plena y certeramente apreciados en el acto de juzgar. La formación científico-técnica de los jueces y la regulación tradicional de la prueba pericial es difícil que garanticen completamente una apreciación de aquella calidad.

c) La masificación y homogeneidad de los conflictos jurídicos que se plantean, pero que, por la gran cantidad de los mismos, han de ser resueltos por un número cada vez más elevado de tribunales, crean un riesgo muy elevado de dispersión y de contradicción entre las resoluciones judiciales, que ponen en peligro el básico principio de igualdad en la aplicación de la norma. Es necesario revitalizar antiguos instrumentos procesales (el recurso de casación) y crearlos nuevos para contrarrestar ese riesgo.

3. Opinión personal sobre la formación jurídica en el inicio del tercer milenio

A mi juicio la formación jurídica en el umbral del tercer milenio deberá responder a las siguientes características generales:

A) Formación en los principios del ordenamiento jurídico o de los ordenamientos jurídicos, principios positivizados en un ámbito universal, en el ámbito de comunidades políticas supranacionales de nivel regional, en el ámbito estatal. Estos principios o fundamentos del o de los ordenamientos son los derechos humanos, su reconocimiento y tutela, y la organización y funcionamiento democráticos de las comunidades políticas.

B) Formación básica de carácter científico-técnico sobre el sistema de fuentes del ordenamiento o de los ordenamientos jurídicos y sobre los diversos contenidos normativos que integran el ordenamiento.

La formación sobre el sistema de fuentes tiene gran importancia porque ha adquirido gran complejidad y es previsible que su complejidad siga aumentando. La simplicidad de un Derecho originado principalmente por el poder del Estado ha sido superada por la concurrencia en la creación jurídica de comunidades políticas supraestatales y de ámbito infraestatal (autonomías políticas dentro de los Estados) y por la existencia de importantes ámbitos de autonomía individual y social.

La formación en los contenidos normativos no debe consistir en una retención de datos normativos y jurisprudenciales, sino el apren- 
dizaje del modo peculiar de razonamiento que conocemos como método científico-jurídico. Pero sería contraproducente para la asimilación de la esencia de lo jurídico intentar que ese aprendizaje se realizara en abstracto, sin relación con normas vigentes en el ámbito en el que el aprendizaje se produce. La formación en contenidos normativos ha de referirse tanto a datos normativos como a métodos de razonar jurídicamente sobre y con esos datos.

Esta formación, que debe realizarse en primer término en la Universidad, ha de comprender la adquisición de un conocimiento teórico de datos, de conceptos, de procedimientos de razonamiento-, pero también ha de incluir, ya en esa etapa universitaria, una preparación para la aplicación de ese conocimiento, de modo que la formación universitaria contribuya a que el estudiante asimile que el Derecho es conocimiento y reflexión pero destinado a la resolución de ciertos problemas de la vida social.

C) Razonablemente la configuración de los planes de estudio universitarios requiere seleccionar los contenidos normativos sobre los que principalmente va a versar la formación. No tiene sentido intentar que ésta se refiera a todos los contenidos. Ahora bien, es necesario reflexionar sobre los criterios de selección y ajustarlos a la realidad actual y a sus rápidas posibilidades de evolución. Han de incluirse materias que permitan a los estudiantes comprender la dimensión jurídica del fenómeno de la mundialización y las transformaciones en el Derecho interno de su comunidad política (por ejemplo: frente a las partes tradicionales del Derecho privado, situarles ante la importancia actual del Derecho de la competencia, de las condiciones generales de la contratación y del Derecho del consumo). La complejidad del ordenamiento y de los ordenamientos aconseja introducir materias en calidad de optativas, pero sin descuidar la mayor importancia de la formación mencionada en los anteriores apartados A y B.

D) A la formación universitaria debe seguir un periodo de formación profesional en el que se potencie la formación en los aspectos técnicos y aplicativos del Derecho y que debe ser en buena parte especializado para cada profesión. Esa formación debe ser impartida principalmente por los profesionales de la misma y de otras profesiones jurídicas.

No obstante, en la ordenación de esta formación -como antes en la de la formación universitaria- ha de tenerse presente que el Derecho ha 
de ser un campo de entendimiento común para todos los profesionales del mismo, incluidos los dedicados a su docencia universitaria.

La formación profesional no puede concebirse como transmisión acrítica de rutinas profesionales, ni como la «verdadera formación jurídica" posterior al requisito del título universitario. Es imprescindible una aproximación recíproca entre la formación universitaria y la formación profesional jurídicas, como existe más tradicionalmente en estudios universitarios técnicos como la arquitectura y las ingenierías.

Por otra parte, es imprescindible una parte común en la formación profesional de todas las profesiones jurídicas, porque todas ellas son ejercidas en relación con las otras, y algunas, como jueces, abogados y miembros del ministerio público, en relación casi necesaria. Conseguir un grado de comunidad de conceptos, de métodos de razonamiento, en definitiva, de lo que se supone el acervo de una determinada ciencia o técnica, contribuirá a la perfección del funcionamiento del sistema jurídico.

E) La inclusión en la formación jurídica universitaria y profesional de conocimientos y adiestramiento en determinada tecnología informática y de la comunicación me parece una situación transitoria, hasta que las capacidades para la utilización de estos nuevos instrumentos sean adquiridas en la formación general. Siempre será conveniente incluir en aquella formación las aplicaciones específicas a la materia jurídica.

F) La complejidad de los ordenamientos jurídicos y la rapidez de los cambios sociales y de los cambios jurídicos, que dan respuesta a los anteriores, imponen como características imprescindibles de la formación jurídica, la especialización y, sobre todo, la formación continuada.

Sobre la primera se ha comentado algo antes.

El ritmo acelerado de modificación de las normas que era, hasta hace poco tiempo, sólo percibido en determinados sectores del ordenamiento (Derecho Administrativo), se ha generalizado a todos los sectores. Pensando en mi contexto nacional, no hay parte del ordenamiento que, en los últimos veinte años, no haya experimentado cambios, incluso profundos. En parte ello se ha debido a razones históricas singulares -cambio constitucional, ingreso en la Comunidad Europea-. Pero -aunque sea efecto indirecto de lo anterior- también ha afectado a todos los sectores del Derecho privado: nuevo Derecho de paternidad y filiación, de la incapacitación, de la adopción y figuras afines, del 
matrimonio y de las llamadas uniones de hecho, sobre préstamos con garantía hipotecaria, nuevo Derecho de sociedades mercantiles, de los instrumentos del tráfico cambiario, nuevo Derecho de la propiedad industrial y de la propiedad intelectual, nuevo Derecho de la competencia, del consumo, de las condiciones generales de la contratación, cambios frecuentes en el régimen jurídico de la contratación laboral, etcétera.

La formación jurídica inicial, universitaria y profesional, no garantiza una adecuado nivel de conocimientos y de aptitudes durante largos períodos de tiempo. Es necesario institucionalizar la formación continuada y fomentar un cambio de actitud de los profesionales jurídicos ante la formación, que no ha de ser vista como algo adquirido, sino como algo a mantener a lo largo de la vida profesional. 